\title{
relA Inactivation Converts Sulfonamides Into Bactericidal Compounds
}

\author{
Lizhen Si ${ }^{1,2}$, Jing $\mathrm{Gu}^{1}$, Mi Wen ${ }^{1,2}$, Ruiqi Wang ${ }^{1,2}$, Joy Fleming ${ }^{3}$, Jinyue $\mathrm{Li}^{1}$, Jintian $\mathrm{Xu}^{1,2}$, \\ Lijun $B i^{3,4,5}$ and Jiaoyu Deng ${ }^{1,5 *}$ \\ ${ }^{1}$ Key Laboratory of Special Pathogens and Biosafety, Wuhan Institute of Virology, Chinese Academy of Sciences, Wuhan, \\ China, ${ }^{2}$ University of Chinese Academy of Sciences, Beijing, China, ${ }^{3}$ Key Laboratory of RNA Biology and National Laboratory \\ of Biomacromolecules, CAS Center for Excellence in Biomacromolecules, Institute of Biophysics, Chinese Academy of \\ Sciences, Beijing, China, ${ }^{4}$ School of Stomatology and Medicine, Foshan University, Foshan, China, ${ }^{5}$ Guangdong Province \\ Key Laboratory of TB Systems Biology and Translational Medicine, Foshan, China
}

OPEN ACCESS

Edited by:

Josep M. Sierra,

University of Barcelona, Spain

Reviewed by:

Fabrizio Carta

University of Florence, Italy

Joanne K. Hobbs,

University of Victoria, Canada

*Correspondence:

Jiaoyu Deng

dengjy@wh.iov.cn

Specialty section:

This article was submitted to Antimicrobials, Resistance and

Chemotherapy,

a section of the journal

Frontiers in Microbiology

Received: 21 April 2021 Accepted: 31 August 2021 Published: 27 September 2021

Citation:

Si L, Gu J, Wen M, Wang R,

Fleming J, Li J, Xu J, Bi L and Deng J (2021) relA Inactivation

Converts Sulfonamides Into

Bactericidal Compounds.

Front. Microbiol. 12:698468.

doi: 10.3389/fmicb.2021.698468
Folates are required for the de novo biosynthesis of purines, thymine, methionine, glycine, and pantothenic acid, key metabolites that bacterial cells cannot survive without. Sulfonamides, which inhibit bacterial folate biosynthesis and are generally considered as bacteriostats, have been extensively used as broad-spectrum antimicrobials for decades. Here we show that, deleting relA in Escherichia coli and other bacterial species converted sulfamethoxazole from a bacteriostat into a bactericide. Not as previously assumed, the bactericidal effect of SMX was not caused by thymine deficiency. When E. coli $\Delta$ relA was treated with SMX, reactive oxygen species and ferrous ion accumulated inside the bacterial cells, which caused extensive DNA double-strand breaks without the involvement of incomplete base excision repair. In addition, sulfamethoxazole showed bactericidal effect against $E$. coli $\mathrm{O} 157 \Delta r$ relA in mice, suggesting the possibility of designing new potentiators for sulfonamides targeting RelA. Thus, our study uncovered the previously unknown bactericidal effects of sulfonamides, which advances our understanding of their mechanisms of action, and will facilitate the designing of new potentiators for them.

Keywords: sulfonamides, RelA, reactive oxygen species, ferrous ion, DNA double-strand breaks, bactericidal effects

\section{INTRODUCTION}

Folate species are one-carbon units involved in the biosynthesis of purines, thymidine, glycine, methionine, and pantothenic acid in both prokaryotes and eukaryotes (Cossins, 2000; Kompis et al., 2005). Although the cellular requirement for folates is universal, prokaryotes and eukaryotes obtain them via different methods. While most microbes are unable to obtain folates from the external environment and must synthesize them de novo, mammals can only obtain folate from their diet (Henderson and Huennekens, 1986). The dichotomy of this essential biosynthetic pathway in humans and microbial pathogens makes it an attractive drug target (Bermingham and Derrick, 2002).

Sulfonamides, i.e., compounds targeting the enzyme dihydropteroate synthase (DHPS) that is involved in the bacterial folate biosynthesis pathway, in common use since the 
1930s, were the first widely used synthetic antimicrobial agents to treat and control numerous bacterial and parasitic infections (Gaudilliere, 2009). As sulfonamides are generally considered to be bacteriostatic drugs (Seydel, 1968), trimethoprim (TMP), which serves as a potentiator, was later approved for clinical use to enhance the efficacy of sulfonamides and reduce the emergence of resistance (Grunberg and DeLorenzo, 1966). To date, SXT [a fixed combined dosage of TMP and sulfamethoxazole (SMX)] remains one of the key antimicrobial agents recommended by the World Health Organization. However, a report showed that sulfonamides also exert bactericidal effects on Escherichia coli when bacterial cells are cultured in minimum medium supplemented with casamino acids and purines (Then and Angehrn, 1973). Thus, after being extensively utilized for several decades, it remains unclear whether sulfonamides are bactericidal. Moreover, resistance to TMP has already emerged (Murray et al., 1982; Toulouse et al., 2020; Manna et al., 2021; Schnetterle et al., 2021), thus, novel potentiators are urgently required to improve the efficacy of SMX and expand its clinical use.

In many bacteria, nutrient starvation, including that of amino acids and fatty acids, stimulates the stringent response, whose hallmark is the accumulation of guanosine $3^{\prime}, 5^{\prime}$-bispyrophosphate (ppGpp), an alarmone and global regulator involved in bacterial stringent response (Chatterji and Ojha, 2001). In gammaproteobacteria, the steady state of ppGpp is maintained by two enzymes, RelA and SpoT. RelA is a synthase, while SpoT is a hydrolase that also exerts low synthase activity (Atkinson et al., 2011). However, most bacteria, including Mycobacterium tuberculosis, exhibit a single bifunctional Rel protein as the major RelA/SpoT homolog (Yi and Kim, 2018). ppGpp profoundly affects cellular processes and is also involved in adaptive antibiotic tolerance, or persistence (Abranches et al., 2009; Honsa et al., 2017; Dutta et al., 2019) typically observed toward bactericides rather than bacteriostats (Brauner et al., 2016). Although sulfonamides are known to block bacterial folate biosynthesis, leading to amino acid starvation in bacterial cells, the impact of ppGpp on the antimicrobial efficacy of sulfonamides has not been probed. Thus, it is imperative to determine if ppGpp affects the antimicrobial efficacy of sulfonamides, particularly the bactericidal effects of sulfonamides.

In this study, we measured the effect of sulfonamides on the relA mutant strains in vitro and in vivo. We found that deleting relA allowed SMX to exert its bactericidal effect on multiple bacterial species, including E. coli, Salmonella enterica, and Mycobacterium tuberculosis. Meanwhile, other sulfonamides, namely sulfamethazine, sulfadoxin, and sulfisoxazole, could also effectively kill the E. coli $\Delta$ relA mutant. Furthermore, SMX also shows a killing effect on $E$. coli $\mathrm{O} 157 \Delta$ relA in vivo. Our results show that the increased accumulation of endogenous reactive oxygen species (ROS) and ferrous ion play crucial roles in the bactericidal effect of SMX, resulting in extensive DNA double-strand breaks (DSBs).

\section{MATERIALS AND METHODS}

\section{Bacterial Strains and Plasmids}

The information of E. coli K-12 W3110, E. coli K-12 BW25113, Salmonella enterica serovar Typhimurium (S. enterica), and $M$. tuberculosis H37Ra strains were listed in Supplementary Table S3. All gene knockout mutant strains of $E$. coli and $S$. enterica were constructed using the $\lambda$ Red Recombination System as described previously (Datsenko and Wanner, 2000; Baba et al., 2006). The construction of mycobacterial mutant was described below. All plasmids, strains, and primers that we used were listed in Supplementary Tables S3-S6.

\section{Construction of Mycobacterial Mutant}

A modified strategy for specialized transduction was used to construct the $M$. tuberculosis $\mathrm{H} 37 \mathrm{Ra} \Delta$ relA mutant according to a previous publication (Bardarov et al., 2002). Genomic regions flanking relA, $820 \mathrm{bp}$ upstream (region containing MRA_2611) and $827 \mathrm{bp}$ downstream (region containing MRA_2613 and MRA_2614), were amplified by PCR. The primers used for amplification of the upstream of relA were relA-LFP and relA-LRP and those for the region downstream were relA-RFP and relA-RRP. The recombinant plasmid p0004s- $\mathrm{L}+\mathrm{R}$ was constructed by inserting the Van91I-digested PCR products into the plasmid p0004s digested with Van91I. Then, the p0004s- $\mathrm{L}+\mathrm{R}$ was digested with PacI and ligated to the PacI-digested shuttle phasmid vector phAE159. After ligation, the recombinant cosmid phAE159-p0004s-L + R was transducted into $E$. coli $\mathrm{HB} 101$ in an in vitro $\lambda$-packaging reaction (Epicentre: MaxPlax Lambda Packaging Extracts). The phasmid DNA prepared from confirmed selected hygromycin-resistant transductants was electroporated into $M$. smegmatis $\mathrm{mc}^{2} 155$ to generate the specialized transducing phage. The transducing phage at the most efficient titer was used to infect H37Ra at multiplicity of infection of 10. Successful specialized transduction of H37Ra was confirmed by comparing the size of the PCR-amplified product of hygromycin-resistant colonies with wild-type H37Ra using primers relA-LYZ and relA-RYZ. The primers we used here were listed in the Supplementary Table S4 and S5.

\section{Viability Assays}

Overnight cultures of $E$. coli and S. enterica were diluted 100 -fold in fresh Luria-Bertani (LB) medium, grown to an $\mathrm{OD}_{600}=0.6$, collected by centrifugation, and washed twice with $\mathrm{E}$ minimal medium $\left(\mathrm{MgSO}_{4} \bullet 7 \mathrm{H}_{2} \mathrm{O}(0.2 \mathrm{~g} / \mathrm{L})\right.$, Citric $\bullet \mathrm{H}_{2} \mathrm{O}$ $(2 \mathrm{~g} / \mathrm{L}), \quad \mathrm{K}_{2} \mathrm{HPO}_{4} \bullet 3 \mathrm{H}_{2} \mathrm{O} \quad(13.09 \mathrm{~g} / \mathrm{L}), \quad \mathrm{NaNH}_{4} \mathrm{HPO}_{4} \bullet 4 \mathrm{H}_{2} \mathrm{O}$ $(3.5 \mathrm{~g} / \mathrm{L})$; Vogel and Bonner, 1956). Cells $\left[10^{6}\right.$ colony forming units (CFUs)/ml] were incubated in $10 \mathrm{ml} \mathrm{E}$ minimal medium with $0.5 \% \quad \mathrm{D}$-(+)-glucose and the appropriate concentration of SMX (appropriate multiples of MIC) at $37^{\circ} \mathrm{C}$ for 6 or 8 days.

Mycobacterium tuberculosis was cultured in 7H9 liquid medium supplemented with $10 \%(\mathrm{v} / \mathrm{v})$ oleic acid-albumindextrose-catalase (OADC), 0.5\% (v/v) glycerol and 0.05\% (v/v) Tween 80 , to log phase $\left(\mathrm{OD}_{600} \sim 0.8\right)$. Cells were washed twice 
in fresh medium, diluted to $\mathrm{OD}_{600}=0.1$ in the same medium, and then treated with $300 \mu \mathrm{g} / \mathrm{ml}$ SMX.

Viable cell number was assessed through colony-formation assays (Kohanski et al., 2007). Hundred microliters cultures were serially diluted in $\mathrm{E}$ minimal medium (E. coli) or $7 \mathrm{H} 9$ (M. tuberculosis). Ten microliters of each dilution was plated on LB (E. coli) or 7H10 (M. tuberculosis) agar plates, and the plates were incubated at $37^{\circ} \mathrm{C}$ overnight (E. coli) or for 4 weeks (M. tuberculosis). $\mathrm{CFU} / \mathrm{ml}$ values were calculated using the formula: $\left[(\text { colonies })^{*}(\right.$ dilution factor $\left.)\right] /($ volume plated in $\mathrm{ml})$. The limit of detection is $100 \mathrm{CFU} / \mathrm{ml}$.

\section{Drug Susceptibility Testing}

E. coli and $S$. enterica cells were grown in LB medium to mid-log phase $\left(\mathrm{OD}_{600}=0.6-0.8\right)$ and washed twice with $\mathrm{E}$ minimal medium. Resuspended cells were then serially diluted to $10^{5} \mathrm{CFU} / \mathrm{ml}$ in fresh $\mathrm{E}$ minimal medium. Ten microliters dilutions were plated on E minimal medium solid plates (1\% agar) containing various concentrations of antibacterial agents. These plates were incubated for approximately $48 \mathrm{~h}$ at $37^{\circ} \mathrm{C}$. The MIC was defined as the lowest concentration of the compound to inhibit $99 \%$ of bacterial growth (measured as CFUs). Three independent replicate assays were performed, three randomly selected colonies being assayed each time. Mycobacterial cells were cultured to $\mathrm{OD}_{600}$ of $0.5-1.0$ and diluted to approximately $10^{5} \mathrm{CFU} / \mathrm{ml}$ by 10 -fold serial dilutions in fresh 7H9 medium with or without $10 \%$ OADC. Bacteria were then plated onto $7 \mathrm{H} 10$ agar solid plates containing various concentrations of SMX.

\section{ROS Measurement}

E. coli K-12 W3110 and E. coli K-12 W3110 $\Delta$ relA were cultured and treated with SMX as described above (viability assay). Cultures were harvested after 8,16 , and $24 \mathrm{~h}$ of SMX treatment. After suspension in E medium, cells were incubated with $10 \mu \mathrm{M} 2^{\prime}, 7^{\prime}$-dichlorodihydrofluorescein diacetate (DCFH$\mathrm{DA}$, a fluorescent ROS indicator) for $20 \mathrm{~min}$ in the dark at $37^{\circ} \mathrm{C}$ and inverted every $5 \mathrm{~min}$. Cells were subsequently washed twice with E medium to remove excess extracellular DCFH-DA. Fluorescence was measured at an excitation wavelength of $488 \mathrm{~nm}$ and an emission wavelength of $525 \mathrm{~nm}$ using a multimode microplate reader (Synergy H1 Hybrid; BioTek, United States). Relative fluorescence was normalized to CFUs. All data represent the mean of three independent replicates.

\section{Internal Ferrous Ion Measurement}

The precipitations of cell cultures with or without SMX treatment were collected through $0.2 \mu \mathrm{m}$ membrane, and then stored in a refrigerator at $-80^{\circ} \mathrm{C}$ overnight $(\sim 12 \mathrm{~h})$. The frozen cells were re-suspended in $200 \mu$ l freshly prepared and precooled $\mathrm{PBS}$, as well as zirconium beads (the ratio of the diameter of $1.5 \mathrm{~mm}$ and $0.5 \mathrm{~mm}$ is $3: 1$ ) whose volume was approximately one third of the PBS. The mixtures were crushed in a cell breaker for $1 \mathrm{~min}$, then immediately incubated on ice for $5 \mathrm{~min}$. The above step was repeated for three times and then samples were centrifuge at $13000 \mathrm{~g}$ for $5 \mathrm{~min}$ at $4^{\circ} \mathrm{C}$. The internal ferrous ion concentration was measured by using the iron assay kit according to the manufacturer's instructions (MAK025).

\section{Visualization of DNA DSBs in SMX-Treated Escherichia coli}

Single cell gel electrophoresis assays are based upon the ability of denatured, cleaved DNA fragments to migrate out of the nucleoid, while undamaged DNA remains confined within the nucleoid (due to their slower migration rates), under the influence of an electric field. DNA damage was assessed by evaluating the DNA comet tail shape and migration pattern (Singh et al., 1999; Solanky and Haydel, 2012; Hieke and Pillai, 2018). Neutral comet assays were performed according to the Trevigen's CometAssay R protocol (Reagent Kit for CometAssay) with modifications.

Wild-type and $\triangle$ relA mutant cells were harvested after incubation with SMX for $0,12,24,36$, and $48 \mathrm{~h}$. Twenty microliters of a $10^{7} \mathrm{CFU} / \mathrm{ml}$ cell suspension was mixed with $200 \mu \mathrm{l}$ LMAgarose, and $50 \mu \mathrm{l}$ of the mixture was pipetted onto a CometSlide. Slides were placed immediately in the dark (at $4^{\circ} \mathrm{C}$ ) until a clear dried ring appeared at the edge of the agarose area. Slides were then placed in a pre-cooled lysis solution and incubated for $1 \mathrm{~h}$ or overnight. Following bacterial lysis, slides were electrophoresed at $20 \mathrm{~V}$ for $20 \mathrm{~min}$ on ice, after gently immersing them in pre-chilled $1 \times$ Neutral Electrophoresis Buffer for $30 \mathrm{~min}$. Slides were then placed in a DNA precipitation solution for $30 \mathrm{~min}$, followed by $70 \%$ ethanol for another $30 \mathrm{~min}$ at $25^{\circ} \mathrm{C}$, and dried at $37^{\circ} \mathrm{C}$. Slides were stained with $50 \mu \mathrm{l} \mathrm{SYBR}$ for $30 \mathrm{~min}$ in the dark and then air-dried at $37^{\circ} \mathrm{C}$ in the dark until totally dry.

Fluorescence was observed by confocal microscopy (Andorra Dragonfly 202) at $\times 630$ magnification. The degree of DNA DSBs was expressed as olive tail moment. The tail moment is a measure of damage that combines the amount of DNA in the tail with the distance of migration. Olive tail moment combines tail moment with the value for the difference in DNA gravity between the head and the tail. Olive tail moment was measured in 80 randomly selected cells using the Comet Analysis software.

\section{Quantitative Real Time PCR}

RNA was extracted using a RNeasy Mini Kit (QIAGEN). cDNA was synthesized using the ReverTra Ace qPCR RT Kit (TOYOBO). qRT-PCR was performed using the Power SYBR Green PCR Master Mix (ABI, 4368708). The expression of the genes of interest was normalized to that of $r r s H$. The primers used in this study were shown in Supplementary Table S6.

\section{Animal Infections and SMX Treatment}

A total of 36 weeks old female BALB/c mice (Vital River Laboratory Animal Technology Co. Ltd., Beijing) were weighed and divided into six groups. All mice were pretreated with $1 \mathrm{~g} / \mathrm{kg}$ streptomycin by gavage once a day for 3 days in order to reduce the natural flora to $10^{3} \mathrm{CFU} / \mathrm{g}$ faeces or less. Half of the mice were then intragastrically infected with $10^{10} \mathrm{CFU}$ of E. coli $\mathrm{O} 157 \mathrm{pBAD} 24$, and the other half with E. coli $\mathrm{O} 157$ 
$\Delta$ relA pBAD24. Two days post infection, all mice faeces were assessed to determine successful colonization by the aforementioned strains. Meanwhile, two groups of mice (one infected with E. coli $\mathrm{O} 157$ pBAD24 and the other with E. coli O157 $\Delta$ relA pBAD24) were euthanized by cervical dislocation, and caecum colonization was determined at the beginning of drug administration. The remaining four groups of mice were then treated with $100 \mathrm{mg} / \mathrm{kg} \mathrm{SMX}$ or $0.9 \% \mathrm{NaCl}$ daily by gavage for 4 days. SMX (Sigma-Aldrich/Merck, Germany) was administered in $0.9 \% \mathrm{NaCl}$ at the concentration of $15 \mathrm{mg} / \mathrm{ml}$. On a daily basis during the course of SMX treatment, fecal colonization was determined. After 4 days of SMX treatment, mice were killed and caecum samples were collected. Fecal and caecum colonization was determined by plating samples on solid LB medium containing ampicillin for viable counts.

\section{Quantification and Statistical Analysis}

Experiments were performed in three biological replicates and at least three technical repetitions. Standard errors were calculated in Microsoft Excel. Visualization of DNA DSBs was observed by confocal microscopy, and the resulting fluorescent (.ims) images was converted to (.tif) images by ImageJ software. Olive tail moment was measured by Comet Analysis software according to the (.tif) images. Graphics were performed in Origin 2018.

\section{RESULTS}

\section{SMX Is Bacteriostatic Toward E. coli, While Deletion of glyA, purH, panB, or metF All Led to Cell Death}

As an antifolate, SMX simultaneously blocks the biosynthesis of purines, thymidine, glycine, methionine, and pantothenic acid (Cossins, 2000). PurH, GlyA, MetF, and PanB are key proteins in the biosynthesis pathways of purines, glycine, methionine, and pantothenic acid, respectively. Deleting purH, glyA, metF, or panB in E. coli caused bacterial cell death, suggesting that bacterial cells cannot survive in the minimal medium without any of these molecules (Supplementary Figure S1A). However, SMX showed bacteriostatic, not bactericidal, effects on wild-type E. coli (Supplementary Figure S1B). These contradictory results indicate that the mechanisms of action of sulfonamides require further investigation.

\section{Deleting relA Makes Sulfonamides Bactericidal}

To determine if ppGpp has a role in the bactericidal effects of SMX, we first disrupted the stringent response by knocking out relA and spoT in E. coli W3110. Consistent with previous reports, the strain $\Delta$ relA $\Delta$ spoT was not able to grow in $\mathrm{E}$ minimal medium (Potrykus et al., 2011). When the viability of $\Delta$ relA and $\Delta$ spot single mutants was examined in the presence of SMX, the cell numbers of the $\Delta$ relA mutant decreased sharply during the first 2 days and were subsequently undetectable, while only a slight difference in the $\Delta$ spoT mutant cell numbers was observed relative to the parental strain (Figure 1A). The killing effect of SMX against the $\Delta$ relA mutant could be completely reversed by introducing a plasmid bearing an intact copy of relA into the mutant (Supplementary Figure S2). We next investigated the viability of the $\Delta$ relA mutant following exposure to three other sulfonamides [sulfamethazine $(80 \mu \mathrm{g} / \mathrm{ml})$, sulfadoxin $(80 \mu \mathrm{g} / \mathrm{ml})$, and sulfisoxazole $(40 \mu \mathrm{g} / \mathrm{ml})]$, and similar bactericidal effects were observed (Figure 1B). In addition, $\Delta$ relA mutants of $E$. coli BW25113, E. coli O157, S. enterica, and M. tuberculosis were treated with SMX and showed an approximately two or three $\log _{10}$ decrease in viable cell numbers compared with their wildtype strains (Figures 1C-F). Moreover, SMX also showed a killing effect on W3110 $\Delta$ relA in LB medium (Supplementary Figure S3). These results indicate that RelA, the main ppGpp synthase, impedes the bactericidal effects of sulfonamides.

\section{Bactericidal Effect of SMX Does Not Depend on Thymineless Death}

When starved of thymine, cells die rapidly (Barner and Cohen, 1957). This phenomenon, called thymineless death, occurs in both prokaryotes and eukaryotes (Ahmad et al., 1998; Khodursky et al., 2015). Theoretically, SMX blocks the biosynthesis of folate and, hence, thymine. To determine whether the bactericidal effect of SMX on $\Delta$ relA mutants is also caused by the lack of thymine, we added exogenous thymine to the growth medium along with SMX. The results indicated that exogenous thymine does not influence the bactericidal ability of SMX (Figure 2A).

\section{2'-Bipyridy and Thiourea Markedly Protect $\triangle$ relA Cells From SMX-Induced Killing}

ppGpp has been shown to affect DNA replication, RNA transcription, ribosome assembly, and the generation of toxic intermediate ROS (Srivatsan and Wang, 2008; Nguyen et al., 2011; Corrigan et al., 2016). Thus, we tested the effects of inhibitors of these processes on the bactericidal ability of SMX. To this end, we added each inhibitor $(0.5 \times \mathrm{MIC}$, Supplementary Table S1) together with SMX to the medium of E. coli $\Delta$ relA and measured the mutant viability. The results showed that, in the presence of the iron chelator 2 '-bipyridy or the ROS scavenger thiourea, the survival number of $E$. coli $\Delta$ relA upon SMX treatment was more than 10 times higher than that of the control group (Figure 2B). However, ofloxacin (a DNA gyrase inhibitor) and rifampicin (an RNA polymerase inhibitor) did not show an increase in bacterial survival. Moreover, contradictory results were obtained for different types of protein synthesis inhibitors: though chloramphenicol could partially reduce the killing caused by SMX, streptomycin and kanamycin significantly potentiated it (Figure 2B). These data suggest that the disruption of ppGpp synthesis may induce ROS accumulation, leading to cell death.

\section{E. coli $\triangle$ relA Accumulates ROS When Treated With SMX}

To further verify if the bactericidal effect of SMX on the $\Delta$ relA mutant is caused by SMX-induced accumulation of ROS, DCFH-DA was used to measure ROS production at 
A

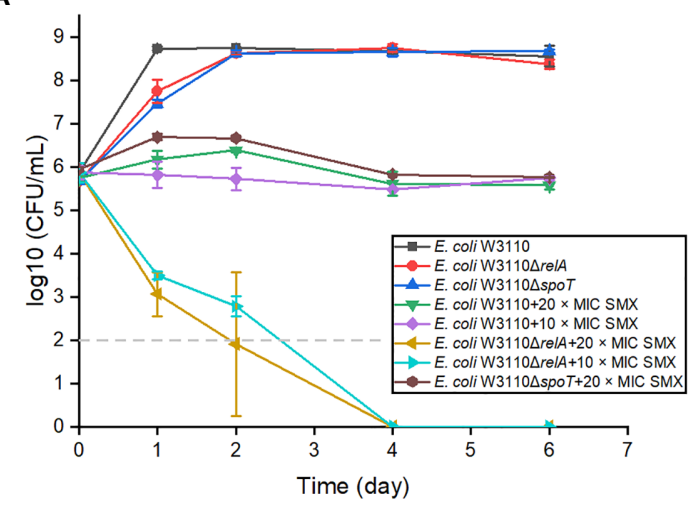

C

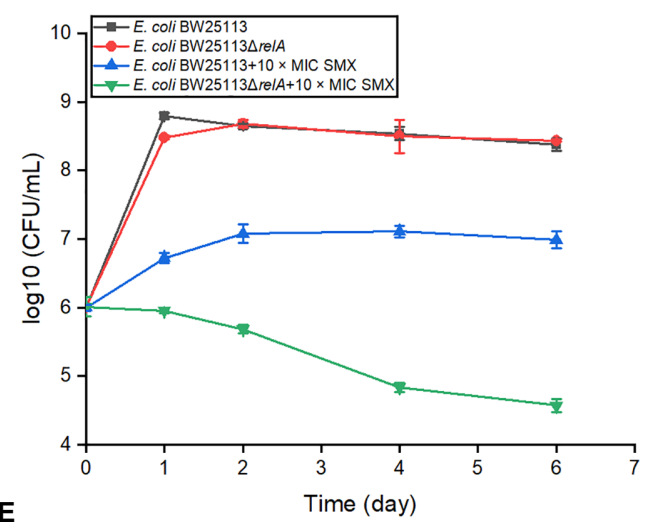

E

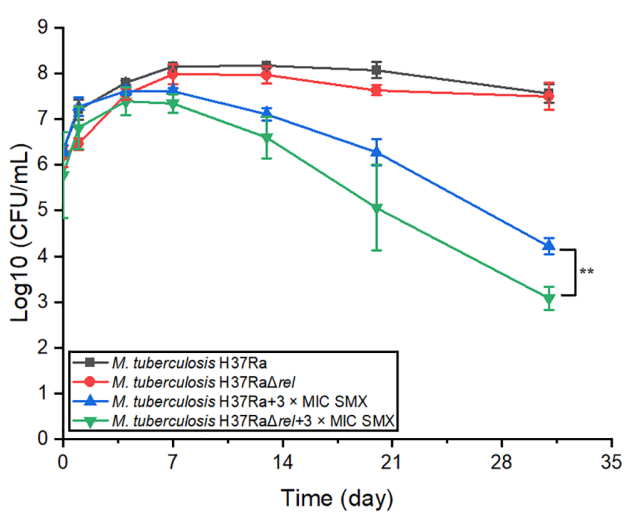

B

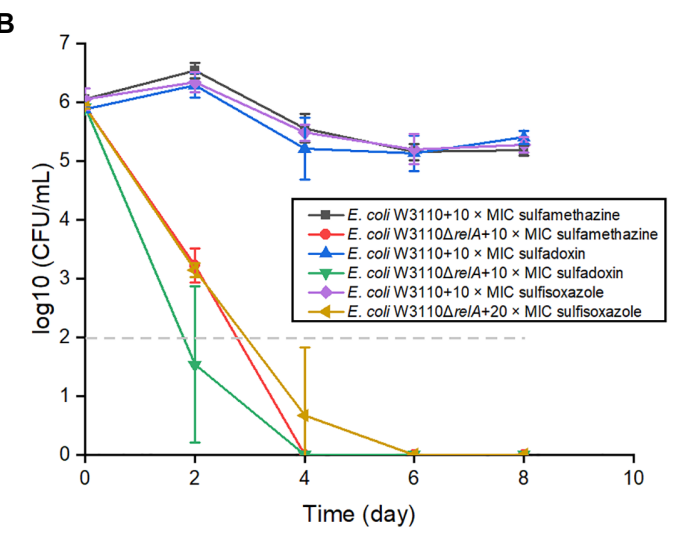

D
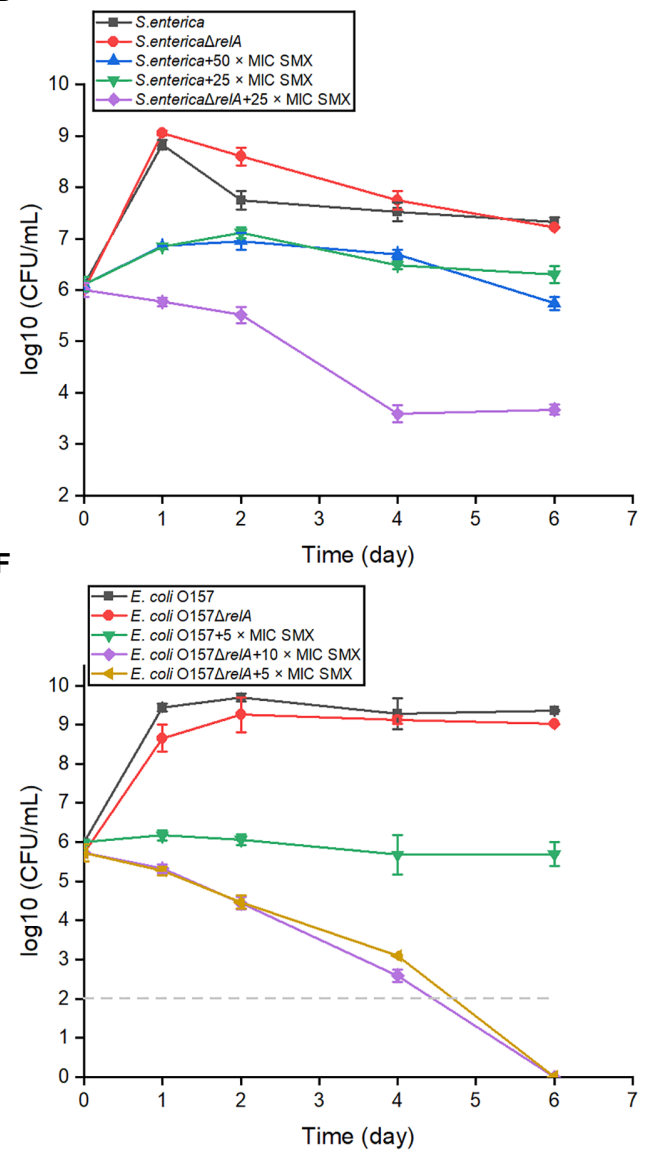

FIGURE 1 | Disrupting the stringent response in different bacterial species converts sulfonamides into bactericides. (A) Two key stringent response genes show disparate effects on the bactericidal effect of SMX in Escherichia coli. (B) Inactivation of relA in E. coli W3110 also converts other sulfonamides into bactericides, including sulfamethazine $(80 \mu \mathrm{g} / \mathrm{ml})$, sulfadoxin $(80 \mu \mathrm{g} / \mathrm{ml})$ and sulfisoxazole $(40 \mu \mathrm{g} / \mathrm{mll})$. SMX shows bactericidal effect on E. coli BW2511 $\Delta$ relA (C), S. typhi $\Delta$ relA (D), M. tuberculosis H37Ra $\triangle$ relA (E), and pathogenic E. coli O157 (F). The MICs of SMX for different bacterial strains were listed in Supplementary Tables S1 and S2. Dashed gray lines represent the limit of detection. In panel (A-D,F), statistical analysis was determined between each $\Delta r e / A$ mutant and its equivalent wild type with SMX treatment at each time point, and the differences were all statistically significant $(p<0.001)$. Statistical analysis was determined by unpaired two-tailed Student's $t$ test $\left({ }^{*} p \leq 0.05,{ }^{\star *} p \leq 0.01, p>0.05\right.$ is not shown). Error bars represent the standard deviation.

different time points in the presence or absence of SMX. Bacterial cells did not accumulate ROS in the absence of SMX (Figure 2C), nor did the wild-type strain in the presence of the drug (Figure 2D). On the contrary, SMX treatment resulted in a significant increase (approximately 3- and 5-fold higher than the ROS production observed in the wild-type strain) in ROS production over time in the $\Delta$ relA mutant (Figure 2D). 
A

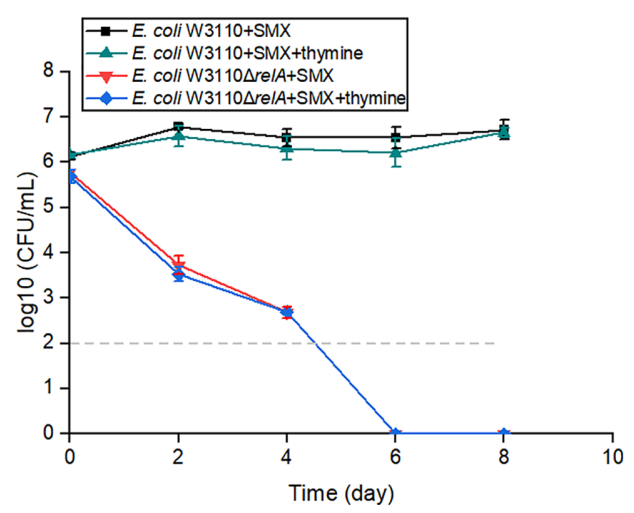

C

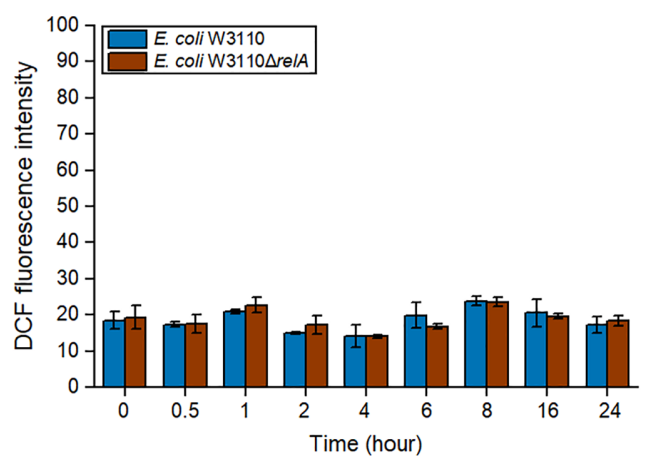

E

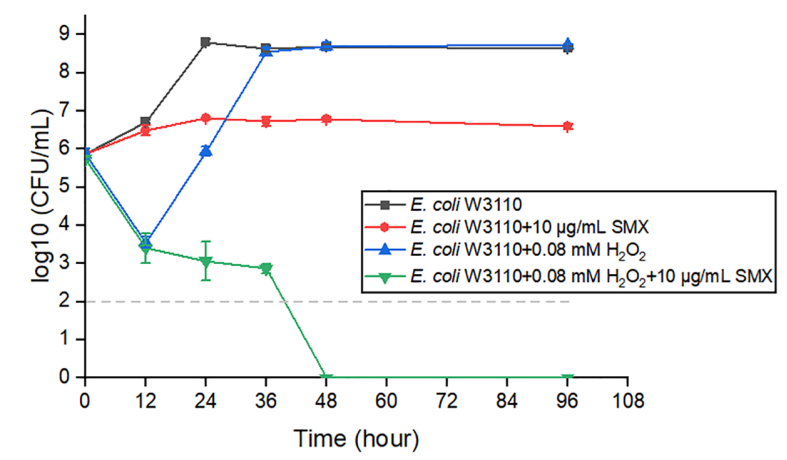

B

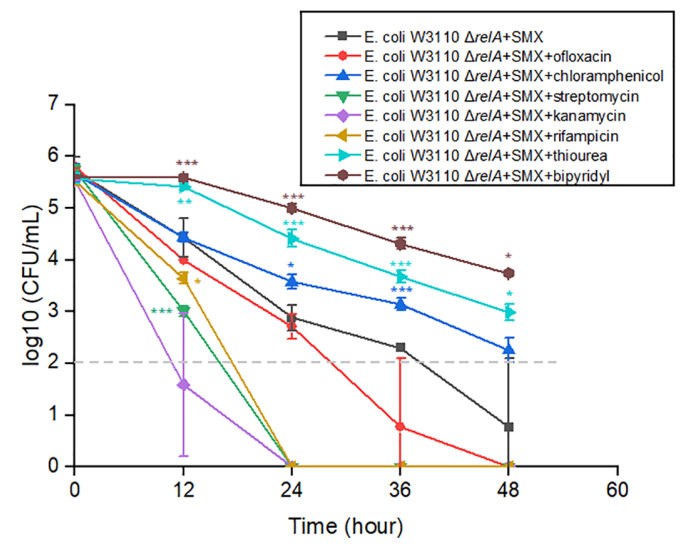

D

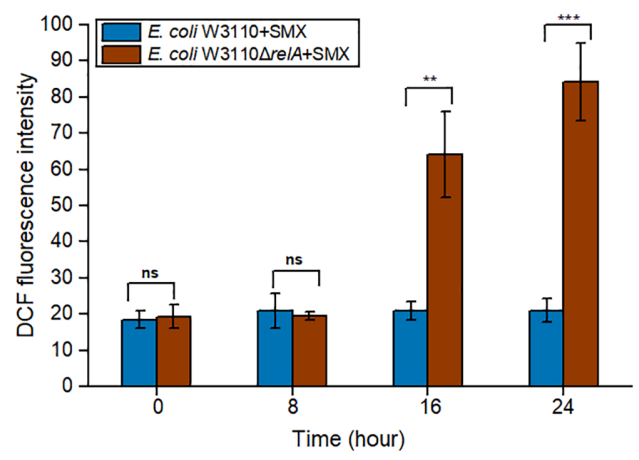

FIGURE 2 | Accumulated ROS, rather than thymine, is responsible for the bactericidal effects of SMX against the $\Delta$ relA mutant. (A) Thymine availability was not related to the killing effect of SMX $(10 \mu \mathrm{g} / \mathrm{ml})$ on the wild type or $\Delta$ relA mutant. The concentration of thymine was $20 \mu \mathrm{g} / \mathrm{ml}$. (B) Effects of seven chemical compounds related with ppGpp functions on the killing effect of SMX $(10 \mu \mathrm{g} / \mathrm{ml})$. ROS production in the wild type and $\Delta$ relA mutant without (C) or with (D) SMX treatment. DCF fluorescence intensity was normalized against bacterial CFUs. (E) $0.08 \mathrm{mM} \mathrm{H}_{2} \mathrm{O}_{2}$ markedly enhances the killing effect of SMX against E. coli W3110. Dashed gray lines represent the limit of detection. Error bars represent the standard deviation. Asterisks indicate statistically significant differences between means as determined by unpaired two-tailed Student's $t$ test $\left({ }^{\star} p \leq 0.05,{ }^{\star \star} p \leq 0.01,{ }^{\star \star \star} p \leq 0.001\right.$; ns, not significant $\left.p>0.05\right)$. In panel $\mathbf{A}$, no statistically significant differences between with/ without thymine were detected for either strain at any time point. In panel $\mathbf{B}$, asterisks of the same color as the line indicate the statistical difference between the strain with compound treatment represented by the line and $\Delta$ relA with SMX treatment, and $p>0.05$ is not shown. In panel $\mathrm{C}$, no statistically significant differences between $\Delta$ relA mutant and wild type at the same time point. In panel E, statistical analysis was determined between $\mathrm{SMX}$ with/without $\mathrm{H}_{2} \mathrm{O}_{2}$, and $p$ value of each time point is less than 0.001 .

\section{Exogenous $\mathrm{H}_{2} \mathrm{O}_{2}$ Makes SMX Bactericidal}

Next, we wondered if exogenous $\mathrm{H}_{2} \mathrm{O}_{2}$ (an important $\mathrm{ROS}$ compound) could also enable SMX to exert a bactericidal effect on E. coli. We found that SMX alone showed bacteriostatic effect on E. coli W3110 during 96 h. When E. coli W3110 was treated with $0.08 \mathrm{mM}$ hydrogen peroxide alone, the viable cell numbers decreased about three logs during the first $12 \mathrm{~h}$. After that, the viable cell numbers increased to the same number 
that without drug treatment at $36 \mathrm{~h}$ (Figure 2E). When E. coli W3110 was treated with SMX plus hydrogen peroxide, the decrease in cell survival was consistent with that treated with hydrogen peroxide alone during the first $12 \mathrm{~h}$ and the viable cell numbers kept on decreasing but slowly till $36 \mathrm{~h}$. After $48 \mathrm{~h}$, the viable cell numbers were below the limit of detection, showing a synergistic effect between these two compounds (Figure 2E).

\section{Interfering With ROS Production by Blocking the Tricarboxylic Acid (TCA) Cycle, Respiratory Chain, ATP Synthase, or Fe-S Cluster Assembly Protects $\Delta r e l A$ From SMX-Induced Killing}

ROS, including superoxide anions $\left(\mathrm{O}_{2}^{-}\right)$, hydrogen peroxide $\left(\mathrm{H}_{2} \mathrm{O}_{2}\right)$, and hydroxyl radicals $(\mathrm{OH} \bullet)$, are the end products of an oxidative damage pathway and are synthesized by the TCA cycle, respiratory chain, and Fenton reaction (Kohanski et al., 2007). Theoretically, the disruption of these processes should suppress ROS production, and thus reverse the bactericidal effect of SMX. To verify this, we constructed a series of double knockout mutants and evaluated their survival in the presence of SMX (Supplementary Figures S4 and S5).

We constructed 10 double knockout mutants, based on the $\triangle$ relA strain, in which TCA cycle-related genes were knocked out $(\Delta a c n A \Delta \operatorname{rel} A, \Delta a c n B \Delta$ relA $, \Delta s d h A \Delta \operatorname{rel} A, \Delta s d h B \Delta r e l A$, $\Delta s d h C \Delta$ relA, $\quad \Delta s d h D \Delta$ relA, $\quad \Delta$ sucC $\Delta$ relA, $\Delta$ sucD $\Delta$ relA, $\Delta$ fumE $\Delta$ relA, and $\Delta m d h \Delta$ relA). As shown in Supplementary Figure S2, $\Delta s d h A \Delta$ relA, $\Delta s d h B \Delta$ relA, $\Delta s d h C \Delta$ relA, $\Delta$ fumE $\Delta$ relA, $\Delta s d h D \Delta$ relA, and $\Delta$ sucC $\Delta$ relA showed a significant increase in survival upon SMX treatment relative to $\triangle$ relA (Supplementary Figures S4A,B). Inactivation of aconitase-encoding gene $a c n A$ or $a c n B$ cannot protect $\Delta r e l A$ from killing by SMX (Supplementary Figures S4C,D). Deletion of $m d h$, the gene encoding malate dehydrogenase, could partially reverse the killing effect of SMX, but the protection was significant only at the first 2 days of drug treatment (Supplementary Figure S4E).

The E. coli aerobic respiratory chain functions with a diverse set of membrane-bound $\mathrm{NADH}$ dehydrogenases on the electron input side and three ubiquinol oxidases on the output side (Bekker et al., 2009). We found that the inactivation of cytochrome bo3 ubiquinol oxidase subunits (CyoA, CyoB, and CyoD) in the $\Delta$ relA mutant did not affect the killing effect of SMX, but deleting cyoC in the $\triangle$ relA mutant could reverse the killing effect of SMX when treated with $10 \mu \mathrm{g} / \mathrm{ml}$ of the drug (Supplementary Figure S5A). Considering that the MIC of SMX for $\Delta r e l A \Delta c y o C$ was two times higher than that of $\Delta r e l A$, the viability of $\Delta$ relA $\Delta$ cyoC following the treatment with $20 \mu \mathrm{g} / \mathrm{ml}$ SMX was also determined, and the reverse effect of $\Delta$ relA $\triangle c y o C$ could only be observed at one time point (day 4; Supplementary Figure S5B). On the other hand, the deletion of $c y d A$ or $c y d B$ (encoding cytochrome bd-I ubiquinol oxidase) in the $\Delta$ relA mutant could obviously reverse the killing effect of SMX (Supplementary Figure S5C). Considering that the protection effect of deleting $c y d B$ is more remarkable than that of deleting $c y d A$, cytochrome bd-I ubiquinol oxidase $(\mathrm{CydB})$ is likely the most important terminal oxidase involved in ROS production in the treatment of the $\Delta$ relA mutant with SMX. In addition, the disruption of NADH dehydrogenases (Ndh, Qor or NuoA) was only able to increase the viability of the $\Delta$ relA mutant at the fourth day of SMX treatment (Supplementary Figure S5C).

Given that ATP synthase synthesizes most of the cellular ATP by utilizing the electrochemical proton gradient formed through the respiratory chain (Nakanishi-Matsui et al., 2016), we likewise examined the viability of the $\Delta a t p C \Delta$ relA mutant when treated with SMX. $\Delta a t p C \Delta$ relA exhibited markedly improved survival compared with $\triangle$ relA (Supplementary Figure S5D). In addition, deleting $\operatorname{gr} x \mathrm{D}$, which affects the assembly of the Fe-S cluster and iron homeostasis (Wang et al., 2012), totally reversed the killing effect of SMX on $\Delta r e l A$ (Supplementary Figure S5D), demonstrating that disrupting the assembly of Fe-S cluster can reverse the bactericidal effect of SMX.

Furthermore, we measured ROS production in these mutants upon SMX treatment. Fluorescence intensity showed that ROS accumulation in the double knockout mutants $\Delta s d h A \Delta r e l A$, $\Delta c y d B \Delta$ relA, $\Delta$ grxD $\Delta$ relA, and $\Delta a t p C \Delta$ relA following SMX treatment was greatly reduced compared with $\Delta$ relA (Supplementary Figure S6). Our data thus suggest that disruption of the TCA cycle, respiratory chain, and Fe-S cluster may interfere with the production of ROS, thereby protecting $\Delta r e l A$ from killing by SMX.

\section{Deletion of relA Leads to Increased Expression of Genes Involved in Fe-S Cluster Biogenesis and Ferrous Ion Accumulation Upon SMX Treatment}

Since ferrous ion is also required for the bactericidal effect of SMX against $\Delta$ relA, we compared the accumulation of ferrous ion upon SMX treatment between the wild-type strain and $\Delta$ relA. The results show that, the amount of ferrous ion accumulated in $\Delta$ relA was two times higher than that of the wild-type strain upon SMX treatment (Figure 3A). Meanwhile, the data of comparative transcriptional analysis show that, SMX treatment caused increased expression of both the iscAUSR and sufABCDES genes (two systems for Fe-S cluster biosynthesis in $E$. coli) in $\triangle$ relA, whereas the same treatment caused increased expression of the sufABCDES genes and decreased expression of iscUSR in the wild-type strain (Figure 3B). Thus, it SMX treatment leads to increased biogenesis of $\mathrm{Fe}-\mathrm{S}$ cluster and ferrous ion accumulation in $\Delta$ relA.

\section{Incomplete BER Does Not Contribute to the Killing Effect of SMX}

ROS are extremely toxic and can readily damage DNA, membrane lipids, and proteins, thereby causing cell death (Dizdaroglu et al., 2002; Imlay, 2003). To date, DNA damage is the best studied form of ROS-related cell damage. Reports in the literature indicate that ROS can damage DNA in different ways and that multiple DNA repair systems, including BER, nucleotide excision repair, and homologous recombination repair, address different types of DNA damage (Jena, 2012). Evaluating the 


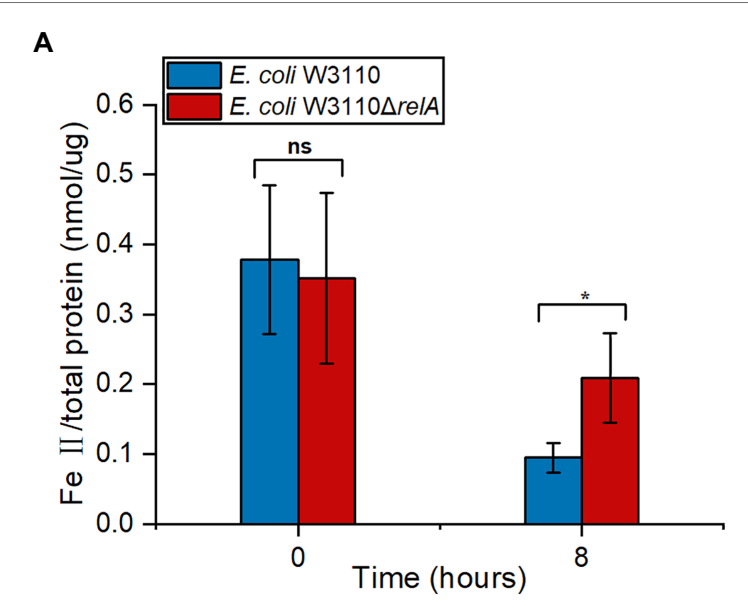

B

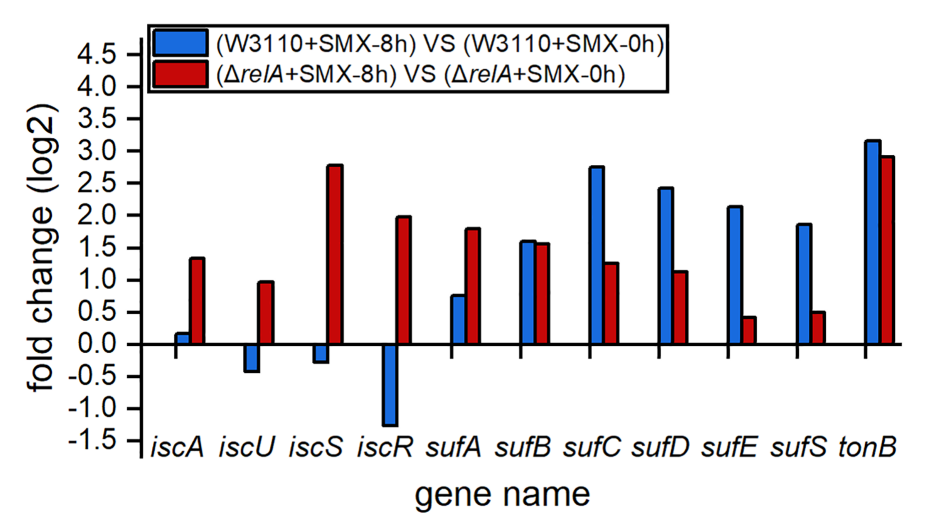

FIGURE 3 | Impacts of RelA on ferrous ion accumulation upon SMX treatment. (A) Internal levels of ferrous iron in $\triangle$ relA and the wild-type strain upon SMX treatment. Asterisks indicate statistically significant differences between means as determined by unpaired two-tailed Student's t test $\left({ }^{\star} p \leq 0.05,{ }^{\star \star} p \leq 0.01\right.$,

${ }^{* \star *} p \leq 0.001 ; \mathrm{ns}$, not significant $p>0.05$ ). Error bars represent the standard deviation. (B) Expression levels of genes associated with iron transport and Fe-S cluster biogenesis.

influence of different DNA repair systems on the bactericidal effect of SMX may help in finding clues as to how ROS accumulation induced by the drug results in bacterial death.

Bases and deoxyribose residues in DNA and free nucleotides in the nucleotide pool are susceptible ROS targets, with guanine being the most susceptible due to its low redox potential (Neeley and Essigmann, 2006). Its oxidized base 8-oxo-deoxyguanosine (8-oxo-dG), the most frequent sign of oxidative DNA damage, can be removed by BER, carried out by the MutT, MutM, and MutY DNA glycosylases. Incomplete BER of 8-oxo-dG is much more problematic than the original damage and contributes to antibiotic-induced lethality (Foti et al., 2012; Dwyer et al., 2014; Giroux et al., 2017; ter Kuile and Hoeksema, 2018). Since SMX inhibits folate biosynthesis, which in turn blocks the biosynthesis of essential nucleotides, including dGTP, we reasoned that it is likely that SMX treatment leads to incomplete BER. If this is the case, further disrupting the BER system would reverse the killing effect of SMX against the $\Delta$ relA mutant. Results showed that SMX only exerted a bacteriostatic effect on the single knockout mutants $\Delta m u t T$, $\Delta m u t M$, and $\Delta m u t Y$, similarly to the parental strain (Supplementary Figure S7A). And further deleting $\Delta m u t T$, $\Delta m u t M$, or $\Delta m u t Y$ could not reverse the killing effect of SMX (Supplementary Figure S7B). On the contrary, further deletion of $m u t M$, or $\Delta m u t T$ in $\Delta$ relA enhanced the killing effect of SMX (Supplementary Figure S7B). These data suggest that BER affect the killing effect of SMX, but incomplete BER does not contribute to the killing effect of SMX.

\section{Components of the Homologous Recombination Repair System Affect the Bactericidal Effect of SMX, Which Is Directly Caused by DNA DSBs}

RecFOR initiates the repair of DNA single-strand breaks and is coupled with RecA homologous recombination (Cox, 2000;
Rocha et al., 2005). We performed viability tests on $\Delta r e c A$ and $\triangle$ recFOR mutants to assess the contribution of singlestrand breaks to the bactericidal effect of SMX. While deleting recA slightly enhanced the bactericidal effect of SMX, deleting recF or recR did not (Figure 4A; Supplementary Figure S8A). Similarly, the deletion of $r e c F$, $r e c R$, or $r e c O$ in $\Delta$ relA could not enhance the killing effect of SMX (Supplementary Figure S8A). These results suggest that singlestrand breaks are not responsible for the lethality induced by SMX.

RecBCD initiates the repair of DNA DSBs, recognizes DSB ends, and is also coupled with RecA homologous recombination (Rocha et al., 2005). After the RecA filament polymerizes on the DSB ends, an exchange of homologous pairs occurs between the damaged DNA and its intact sister duplex. The resulting recombination repair intermediates are subsequently resolved by either the RuvABC complex or the RecG helicase (Kuong and Kuzminov, 2010; Azeroglu et al., 2016). Here, we found that the deletion of $\operatorname{rec} B C D$ (Figure 4B) and $r u v A B C$ (Figure 4C) in wild-type W3110 enabled SMX to exert a killing effect on E. coli, whereas that of recG did not (Supplementary Figure S8B). These results strongly suggest that DNA DSBs contribute to the bactericidal effect of this drug, since RecA, RecBCD and RuvABC are responsible for the repair of DNA DSBs. Meanwhile, it seems that SMX can induce DNA DSBs in both the wild-type strain and the $\Delta$ relA mutant. We thus visualized DNA DSBs following SMX treatment using the neutral comet assay (Supplementary Figure S9), and subsequent statistical analysis showed that the olive tail moment of the wild-type strain peaked at $24 \mathrm{~h}$, decreasing after $12 \mathrm{~h}$ and subsequently maintaining its level (Figure 5). The numbers of DNA DSBs were higher in the $\Delta$ relA mutant than in the wild-type strain (Figure 5). These data suggest that the number of DNA DSBs generated in the wild-type strain upon treatment with SMX did not exceed the repair capacity of the recombinational repair system (Mahaseth and Kuzminov, 2016), while extensive DNA DSBs led to $\Delta$ relA cell death. 
A

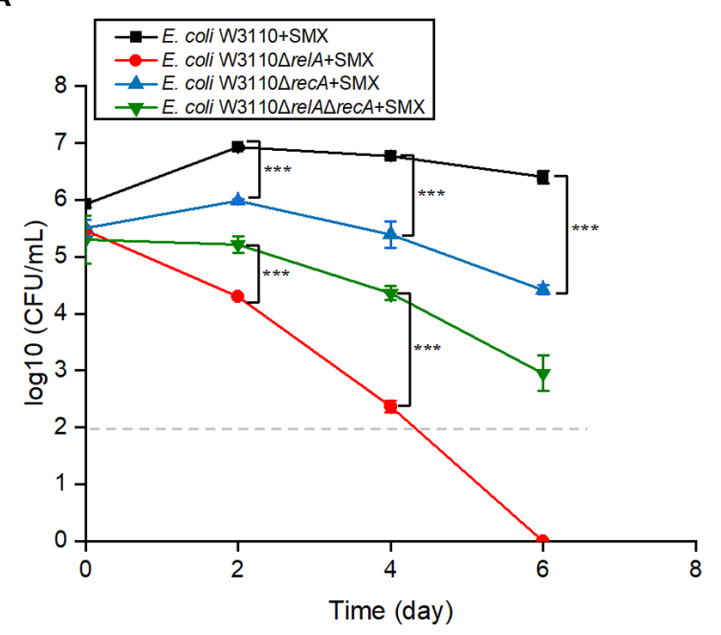

C

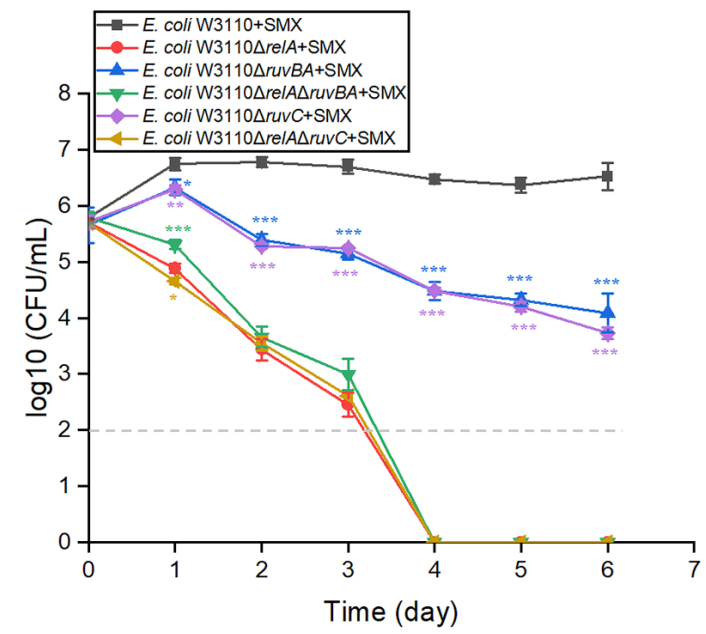

B

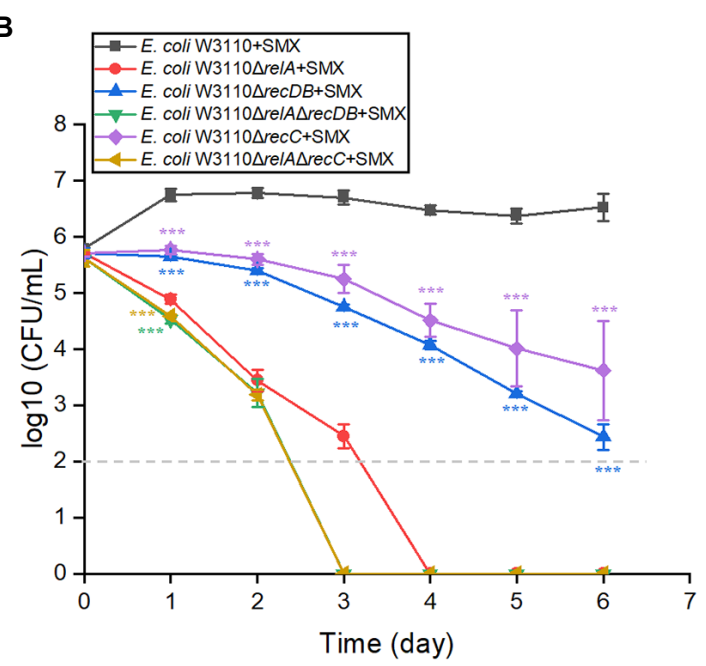

E

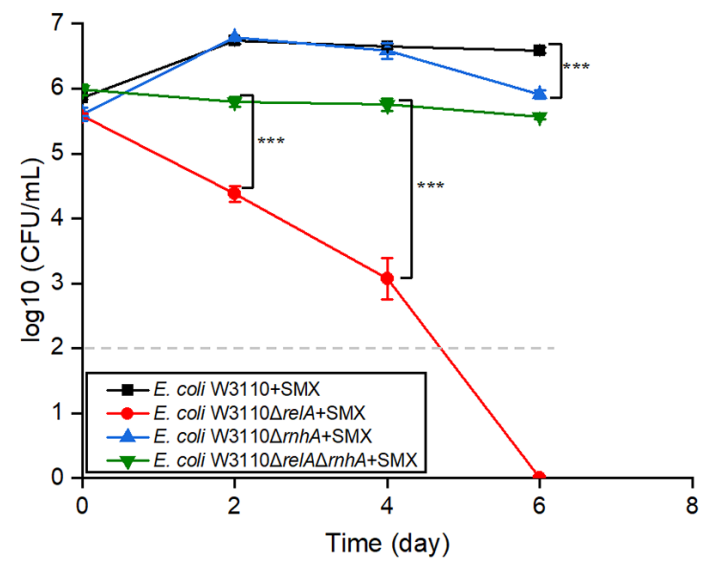

D

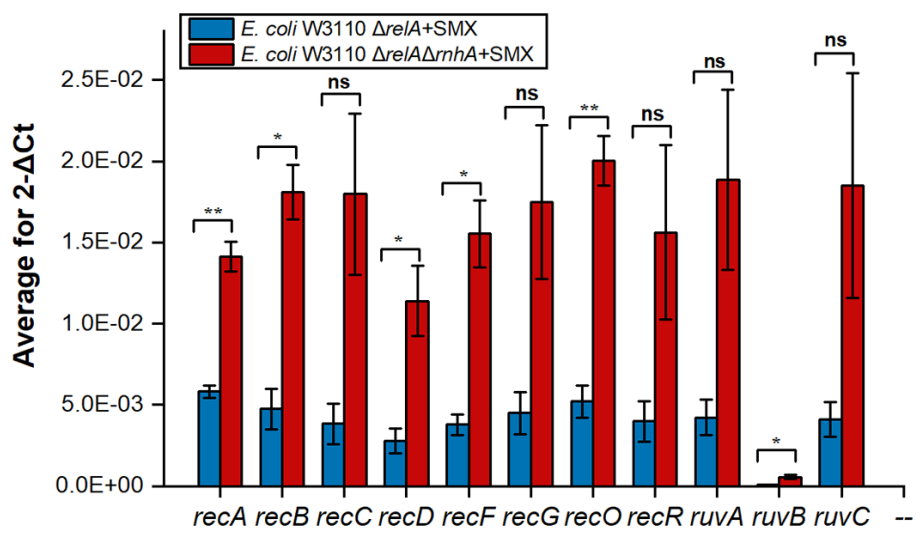

gene name

FIGURE 4 | Disruption of the DNA DSB repair system leads to significantly decreased viability in E. coli and E. coli $\Delta$ relA upon SMX treatment. (A-C) Homologous recombination repair mediates the bactericidal effect of SMX $(10 \mu \mathrm{g} / \mathrm{ml})$. (D) Expression levels of homologous recombination repair genes in the $\Delta$ relA and $\Delta r e / A \Delta r n h A$ mutants (RT-PCR). (E) Deletion of $r n h A$ reverses the bactericidal effect of SMX on the $\Delta$ relA mutant. Dashed gray lines represent the limit of detection. Error bars represent the standard deviation. In panel $\mathbf{( B , C )}$, single gene mutant was compared with wild type, while double gene mutant was compared with $\Delta r$ relA; asterisks of the same color as the line indicate the statistical difference between the strain represented by the line and the control with SMX treatment $(p>0.05$ is not shown). Statistical analysis was determined by unpaired two-tailed Student's $t$ test $\left({ }^{\star} p \leq 0.05,{ }^{* \star} p \leq 0.01,{ }^{\star \star \star} p \leq 0.001\right.$; ns, not significant). 
In addition, we tried to induce the expression of genes related to DNA DSB repair in the $\Delta$ relA mutant by further deleting the RNase HI-encoding gene $r n h A$, which has been shown to be involved in the induction of $\operatorname{rec} B C D$ (Kogoma et al., 1993). As expected, the expression levels of DNA DSB repair genes, such as $\operatorname{rec} A, \operatorname{rec} B, \operatorname{rec} D$, and $\operatorname{ruv} B$, were higher in $\Delta r n h A \Delta r e l A$ than in $\Delta$ relA (Figure 4D), and the deletion of $r n h A$ in the $\Delta$ relA mutant almost completely reversed the killing effect of SMX, though deleting it in the wild-type strain did not show any effect (Figure 4E). Thus, our data strongly suggest that the homologous recombination system plays an important role in protecting against the lethal effects of SMX and that extensive DNA DSBs caused by SMX are the direct cause of cell death.

\section{SMX Shows a Bactericidal Effect on $E$. coli $0157 \Delta$ relA in Mice}

To further verify whether relA gene deletion would affect the bactericidal effect of SMX in vivo, the efficacy of SMX against E. coli O157 $\Delta$ relA was also determined in mice. Two days post infection, the number of both $\mathrm{O} 157$ and $\mathrm{O} 157 \Delta$ relA in the caecum as well as the faeces increased to about $10^{9} \mathrm{CFU} / \mathrm{g}$, suggesting the success of colonization (Figures 6A,B). After 4 days of SMX treatment $(100 \mathrm{mg} / \mathrm{kg})$, a bactericidal effect of the drug was observed on E. coli O157 $\Delta$ relA: viable bacterial counts decreased to about $10^{5} \mathrm{CFU} / \mathrm{g}$ in the caecum and $10^{6} \mathrm{CFU} / \mathrm{g}$ in the faeces, which were nearly three logs less than those of the untreated control groups (Figures 6A,B). However, no such bactericidal effect of SMX could be observed on the wildtype strain.

\section{DISCUSSION}

As broad-spectrum antimicrobials, sulfonamides have been extensively utilized clinically for more than half a century. However, it remains obscure whether these old antimicrobial agents are bactericidal. Sulfonamides are generally considered bacteriostatic drugs (Then and Angehrn, 1973); accordingly, we did not observe a bactericidal effect of SMX on E. coli W3110. Nevertheless, we also found that bacterial cells could not survive when the synthesis of purines, thymidine, glycine, methionine, or pantothenate was blocked. These contradicting results indicate that the mechanisms of action of sulfonamides require further investigation.

Usually, nutrient starvation (including amino acid starvation) in bacteria induces stringent response mediated by ppGpp. Therefore, we speculated that stringent response might impede the bactericidal effects of sulfonamides. As expected, disrupting the stringent response allowed SMX and different types of sulfonamides to exert their bactericidal effect on three different bacterial species and $E$. coli, respectively. We need to mention that, although SMX exhibits killing activity against $\Delta$ relA, it is very slow, which does not meet the usual definition of bactericidal (Pankey and Sabath, 2004; Balouiri et al., 2016). So, in this study, we used "bactericidal" to mean that SMX

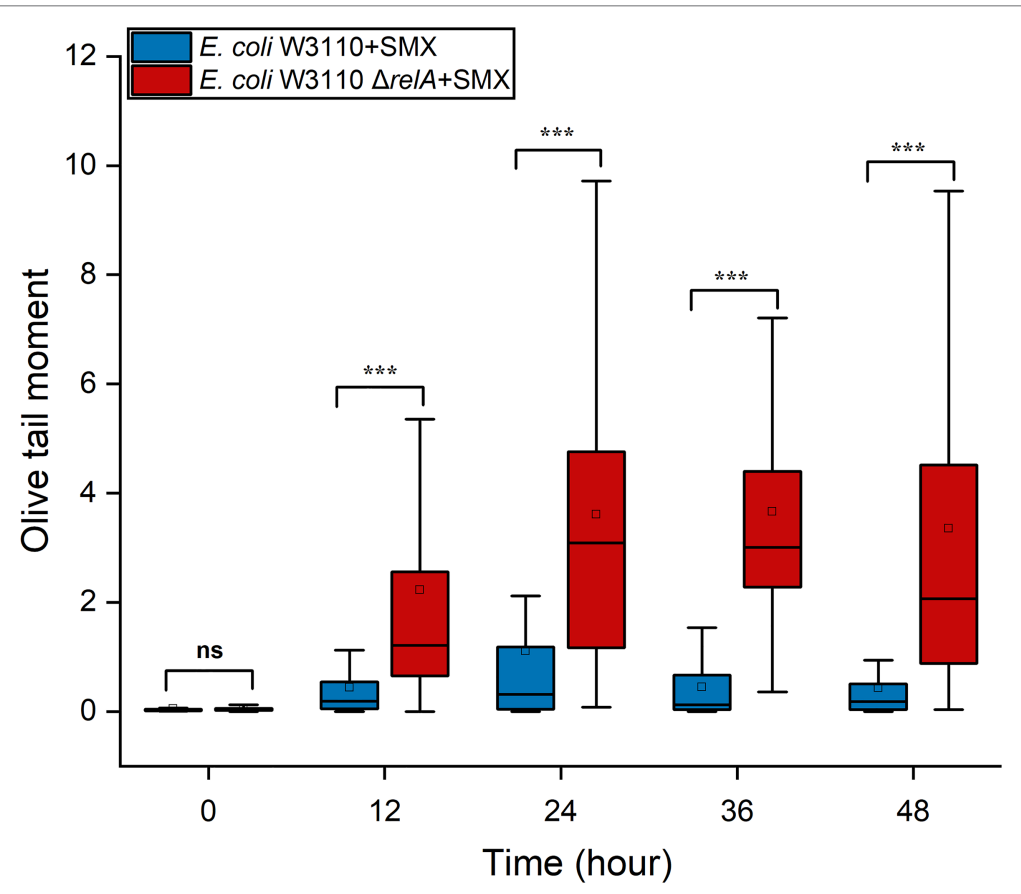

FIGURE 5 | SMX treatment induces extensive DNA DSBs in the $\triangle$ relA mutant. Box-plot of Olive tail moment levels of DNA from wild-type $E$. coli and the $\triangle$ relA mutant treated with SMX $(10 \mu \mathrm{g} / \mathrm{ml})$. The horizontal line inside the box indicates the median of 80 cells, and the average is shown by the small square above the median line. Asterisks indicate statistically significant differences between means as determined by unpaired two-tailed Student's $t$ test $\left({ }^{*} p \leq 0.05,{ }^{* *} p \leq 0.01\right.$, ${ }^{\star \star \star} p \leq 0.001$; ns, not significant $\left.p>0.05\right)$. 
A

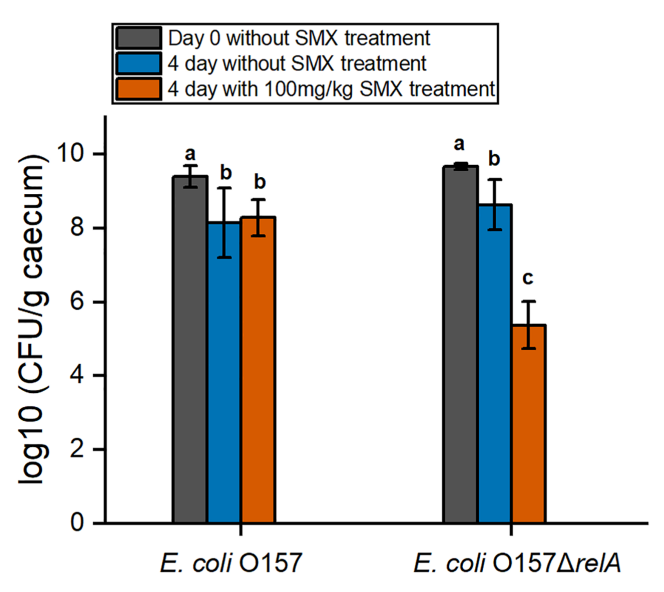

B

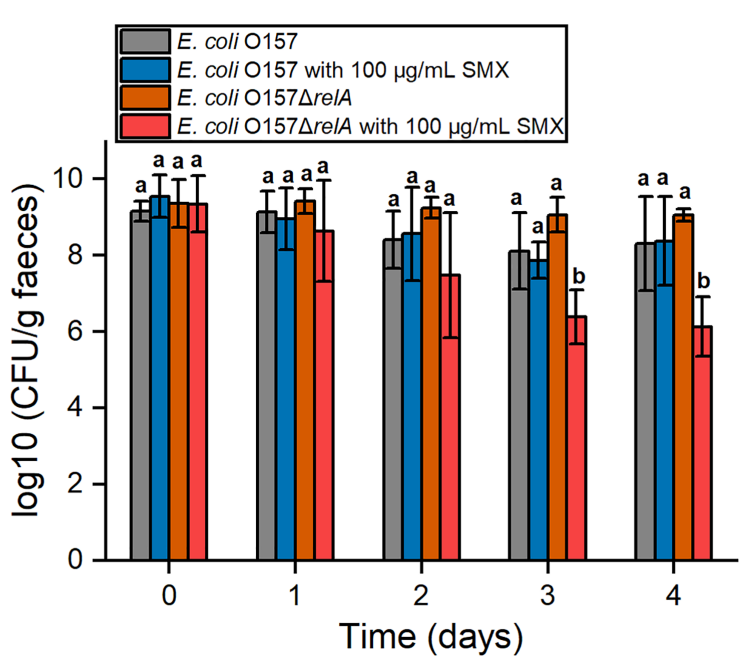

FIGURE 6 | In vivo efficacy of SMX against E. coli 0157 and E. coli O157 $\Delta$ relA. (A) Viable bacterial cell counts in cecal samples. The day begins from the time of intragastrical administration. (B) Viable bacterial cell counts in fecal samples. Letters above bars indicate statistically significant differences between means, as determined by one-way analysis of variance (ANOVA) followed by Tukey's multiple comparison tests among time points for each strain (A) or among strains at each time point (B). Error bars represent the standard deviation.

kills bacteria, rather than just stopping them from growing like bacteriostat. Thus, these results demonstrate that stringent response indeed impedes the bactericidal effects of sulfonamides.

Years ago, research showed that cells die rapidly when thymine is absent (Barner and Cohen, 1957). It was also considered that the conversion of multiple nutrient deficiencies caused by SMX to single thymine deficiency could lead to cell death (Cohen and Barner, 1956). Accordingly, the killing effect of SMX was observed when bacterial cells were treated with this drug in minimal medium supplemented with casamino acids and purine, and thus bacterial death occurring under these circumstances was considered to be thymineless death (Then and Angehrn, 1973; Then, 1980; Amyes, 1982). When thymine is deficient, uracil is incorporated into newly replicated DNA. Afterwards, a futile cycle of uracil removal by uracil DNA glycosylase (Ung) and repair of the resulting gaps results in the incorporation of more uracil, eventually leading to fragmented DNA and cell death. Thymineless death can thus be rescued by ung deletion or addition of exogenous thymine (Khodursky et al., 2015). Here, however, the addition of exogenous thymine had no impact on the killing effect of SMX on the $\triangle$ relA mutant, showing that the bactericidal effect of SMX does not depend on thymineless death.

Previously, it was shown that ppGpp can affect antibiotic tolerance by modulating multiple physiological processes (Srivatsan and Wang, 2008; Nguyen et al., 2011; Corrigan et al., 2016); thus, interfering with these processes using their corresponding inhibitors may also diminish the bactericidal effect of SMX on E. coli $\Delta$ relA. Indeed, $2^{\prime}$-bipyridy and thiourea markedly reversed the bactericidal effect of SMX. 2'-Bipyridy can block Fenton reaction-mediated ROS formation by sequestering unbound iron (Imlay et al., 1988), while thiourea can mitigate the effects of ROS damage in both eukaryotes and prokaryotes (Repine et al., 1981; Takahashi et al., 2005). Thus, we speculated that SMX may induce accumulation of ROS in $\Delta$ relA mutant cells and thus cause cell death. We verified this by measuring ROS production upon SMX treatment and further disrupting the endogenous ROS generation process. Interestingly, we found that SMX also exerted bactericidal effects on E. coli W3110 in the presence of exogenous $\mathrm{H}_{2} \mathrm{O}_{2}$, indicating a potential synergistic effect of these two compounds. The contradictory results observed upon the use of different protein synthesis inhibitors might be explained by their capacity to form free radical. Although chloramphenicol, kanamycin and streptomycin are all ribosome inhibitors, the first compound is bacteriostatic agent, while the last two compounds are bactericidal agents. Bactericidal agents can accelerate basal respiratory and lead to produce deleterious ROS, while bacteriostatic agents decelerate respiratory (Dwyer et al., 2014; Lobritz et al., 2015). Interactions between aminoglycosides (like kanamycin and streptomycin) and the ribosome result in protein mistranslation, causing phosphorylation of CpxA and further activation of ArcA, which in turn provokes free radical formation and culminates in cell death (Kohanski et al., 2008). Though bactericidal drugs rather than bacteriostats were generally considered to produce ROS (Kohanski et al., 2007), our results showed that the well-known bacteriostat SMX can also induce ROS accumulation when the bacterial stringent response is disrupted.

Generally, endogenous ROS are generated through aerobic respiration (Imlay and Fridovich, 1991). As the main terminal oxidases of the respiratory chain, CydA and CydB are important contributors to the production of endogenous ROS. Therefore, it was expected that the deletion of $c y d A / B$ could protect $E$. coli $\Delta$ relA from killing by SMX. Cytochrome bd-I ubiquinol oxidase catalyzes the two-electron oxidation of ubiquinol and 
the four-electron reduction of oxygen to water. Since ubiquinol production is mainly dependent on the catalytic synthesis of succinate dehydrogenase (SdhA, SdhB, SdhC, and SdhD) in the TCA cycle, it was not surprising to observe that the deletion of succinate dehydrogenase-encoding genes in the $\Delta$ relA mutant also greatly reduced the killing effect of SMX. Interestingly, the inactivation of succinyl-CoA synthetase (SucC) also partially reversed the killing effect of SMX, possibly due to insufficient substrate supply for succinate dehydrogenase. Moreover, further deletion of $m d h$, the gene encoding malate dehydrogenase, which catalyzes NADH production in the TCA cycle, also partially reversed the killing effect of SMX. However, further deletion of the aconitase-encoding gene $\operatorname{acn} A / B$ did not affect the killing effect of SMX on the $\Delta$ relA mutant. The deletion of $a c n B$ has previously been shown to quench ROS production and thus reverse the bactericidal effects of multiple antibiotics, probably by affecting bacterial NADH production (Kohanski et al., 2007). Conversely, the inactivation of aconitase has also been shown to cause the accumulation of citrate (Noster et al., 2019), which can promote the production of ROS (Gutteridge, 1990; van de Wier et al., 2013). These two opposite effects may have cancelled each other out when bacterial cells were treated with SMX. Previous research showed that ppGpp mediated suppression of central metabolism could reduce ROS production in Vibrio cholera, thereby increase antibiotic tolerance (Kim et al., 2018). Our data indicated that, when bacterial ppGpp synthesis was blocked, the TCA cycle, respiration and energy consumption in bacterial cell might accelerate upon SMX treatment, thus causing the accumulation of ROS.

Interestingly, we found that further deletion of fumE, the gene encoding a putative fumarase that contains the Fe-S cluster (Flint et al., 1993; Tseng et al., 2001), almost completely protected $\Delta$ relA from killing by SMX. Since E. coli harbors several copies of fumarase (FumA/B/C/D/E), it is likely that FumE serves as a ferrous iron donor. We also found that the deletion of GrxD, involved in Fe-S assembly, in the $\Delta$ relA mutant markedly reversed the killing effect of SMX. Furthermore, we found that upon SMX treatment, $\Delta$ relA accumulated two times more ferrous ion than that of the wild-type strain. These data in combination with that of $2^{\prime}$-bipyridy strongly suggest that ferrous ion is also required for the bactericidal effect of SMX.

ROS accumulation can cause various types of DNA damage, activating elaborate DNA damage repair systems. The disruption of different DNA damage repair systems can thus be used to provide insight into the type of DNA damage that ROS induce upon SMX treatment. When testing the BER system, we found that the deletion of mutM or mutT enhanced the killing effect of SMX. This suggests that while incomplete BER is not the cause of cell death, un-removed oxidized bases in DNA impact the killing effect of SMX. Moreover, a discrepancy between different components of NER was observed possibly due to the different roles played by the three E. coli BER genes ( $\mathrm{Lu}$ et al., 2001; Dwyer et al., 2009): MutT phosphatase removes 8-oxo-dG from the nucleotide pool through hydrolyzing 8-oxo-dG triphosphate to 8-oxo-dG monophosphate in order to prevent its incorporation into DNA during replication; MutM glycosylase recognizes and excises 8-oxo-dG from DNA when paired with
C, G, or T but not with A; MutY glycosylase removes adenine nucleotides paired with 8-oxo-dG. The 8-oxo-G adduct provides a locus for further attack by ROS and reactive nitrogen species, yielding a serial of DNA hyper-oxidation products. This may possibly explain why further deletion of mut $T$ or $m u t M$ in the $\Delta$ relA strain could enhance the killing effect of SMX. However, disrupting the BER system could not reverse the killing effect of SMX.

In addition to oxidizing free nucleotides, bases, and deoxyribose residues in DNA, ROS can directly generate DNA DSBs. Fe (II) bound to DNA reacts with hydrogen peroxide, producing hydroxyl radicals that preferentially target the sugar-phosphate backbone of DNA. If another Fenton reaction occurs with the same iron atom, another hydroxyl radical is generated nearby, creating a DNA DSB (Mahaseth and Kuzminov, 2016). When examining the homologous recombination repair system, which is responsible for repairing DNA single-strand or DSBs, we found that RecFOR did not exert a significant impact on the killing effect of SMX against wild type, but RecBCD and RuvABC markedly affected it. Subsequently, we compared the number of DNA DSBs between the wild-type strain and the $\Delta$ relA mutant upon SMX treatment. Results clearly showed that SMX treatment generated more DNA DSBs in the $\Delta$ relA mutant than that in wild type. In addition, we activated the homologous recombination repair system by inactivating its known repressor RhnA, which almost completely reversed the killing effect of SMX on the $\Delta$ relA mutant. Altogether, these data strongly suggest that SMX-induced accumulated ROS generate DNA DSBs, which is the direct cause of bacterial cell death. Based on a previously published observation, in which damaged bases in DNA were found to impede nonhomologous end joining (a crucial pathway involved in DNA DSB repair; Datta et al., 2011), we speculate that un-removed oxidized bases in DNA might also impede the homologous recombination process, possibly explaining why the disruption of the BER system significantly enhances the killing effect of SMX.

Taken together, our findings show that disrupting the stringent response in different bacterial species, including E. coli, enables the bactericidal effect of well-known bacteriostat sulfonamides. Unlike the bactericidal effect of the other antifolate TMP, that of SMX does not rely on thymineless death. So far, the bactericidal effects of many commonly used antibiotics have been shown to be dependent on ROS through the Fenton reaction. This is the first report showing that the bactericidal effects of the well-known bacteriostat sulfonamides can also induce the accumulation of both ROS and ferrous ion, which induces DNA DSBs without incomplete BER involvement. However, the mechanism of accumulation of ROS and ferrous ion upon SMX treatment in stringent response mutant strain requires further investigation. What's more, as SMX also exerts bactericidal effect on E. coli O157 $\Delta$ relA in vivo, and the ppGpp-mediated stringent response only occurs in prokaryotes, it is plausible that the design of new inhibitors of ppGpp synthases, such as RelA, will yield novel potentiators of sulfonamides. This study deepens our understanding of the mechanisms of action of sulfonamides and will facilitate the design of new potentiators of these compounds. 


\section{DATA AVAILABILITY STATEMENT}

The original contributions presented in the study are included in the article/Supplementary Material, further inquiries can be directed to the corresponding author.

\section{ETHICS STATEMENT}

The animal study was reviewed and approved by Institutional Review Board, Wuhan Institute of Virology, Chinese Academy of Sciences.

\section{AUTHOR CONTRIBUTIONS}

LS and JD designed the studies, wrote the manuscript, performed the data analysis, and acquired high resolution

\section{REFERENCES}

Abranches, J., Martinez, A. R., Kajfasz, J. K., Chavez, V., Garsin, D. A., and Lemos, J. A. (2009). The molecular alarmone (p)ppGpp mediates stress responses, vancomycin tolerance, and virulence in enterococcus faecalis. $J$. Bacteriol. 191, 2248-2256. doi: 10.1128/jb.01726-08

Ahmad, S. I., Kirk, S. H., and Eisenstark, A. (1998). Thymine metabolism and thymineless death in prokaryotes and eukaryotes. Annu. Rev. Microbiol. 52, 591-625. doi: 10.1146/annurev.micro.52.1.591

Amyes, S. G. B. (1982). Bactericidal activity of trimethoprim alone and in combination with sulfamethoxazole on susceptible and resistant Escherichia coli k-12. Antimicrob. Agents Chemother. 21, 288-293. doi: 10.1128/AAC.21.2.288

Atkinson, G. C., Tenson, T., and Hauryliuk, V. (2011). The RelA/SpoT homolog (RSH) superfamily: distribution and functional evolution of ppGpp synthetases and hydrolases across the tree of life. PLoS One 6:e23479. doi: 10.1371/ journal.pone.0023479

Azeroglu, B., Mawer, J. S. P., Cockram, C. A., White, M. A., Hasan, A. M. M., Filatenkova, M., et al. (2016). RecG directs DNA synthesis during double-strand break repair. PLoS Genet. 12:e1005799. doi: 10.1371/journal. pgen.1005799

Baba, T., Ara, T., Hasegawa, M., Takai, Y., Okumura, Y., Baba, M., et al. (2006). Construction of Escherichia coli K-12 in-frame, single-gene knockout mutants: the Keio collection. Mol. Syst. Biol. 2:11, 16738554. doi: 10.1038/msb4100050

Balouiri, M., Sadiki, M., and Ibnsouda, S. K. (2016). Methods for in vitro evaluating antimicrobial activity: a review. J. Pharm. Anal. 6, 71-79. doi: 10.1016/j.jpha.2015.11.005

Bardarov, S., Bardarov, S., Pavelka, M. S., Sambandamurthy, V., Larsen, M., Tufariello, J., et al. (2002). Specialized transduction: an efficient method for generating marked and unmarked targeted gene disruptions in Mycobacterium tuberculosis, M. bovis BCG and M. smegmatis. Microbiology 148, 3007-3017. doi: 10.1099/00221287-148-10-3007

Barner, H. D., and Cohen, S. S. (1957). The isolation and properties of amino acid requiring mutants of a thymineless bacterium. J. Bacteriol. 74, 350-355. doi: $10.1128 /$ jb.74.3.350-355.1957

Bekker, M., de Vries, S., Ter Beek, A., Hellingwerf, K. J., and de Mattos, M. J. T. (2009). Respiration of Escherichia coli can be fully uncoupled via the nonelectrogenic terminal cytochrome bd-II oxidase. J. Bacteriol. 191, 5510-5517. doi: $10.1128 / \mathrm{Jb} .00562-09$

Bermingham, A., and Derrick, J. P. (2002). The folic acid biosynthesis pathway in bacteria: evaluation of potential for antibacterial drug discovery. BioEssays 24, 637-648. doi: 10.1002/bies.10114

Brauner, A., Fridman, O., Gefen, O., and Balaban, N. Q. (2016). Distinguishing between resistance, tolerance and persistence to antibiotic treatment. Nat. Rev. Microbiol. 14, 320-330. doi: 10.1038/nrmicro.2016.34 figures. LS carried out the experiments in the assistance of JG, MW, JL, RW, and JX. JF and LB revised the manuscript. All authors contributed to the article and approved the submitted version.

\section{FUNDING}

This work was supported by the Strategic Priority Research Program of the Chinese Academy of Sciences (grant no. XDB29020000).

\section{SUPPLEMENTARY MATERIAL}

The Supplementary Material for this article can be found online at: https://www.frontiersin.org/articles/10.3389/fmicb.2021.698468/ full\#supplementary-material

Chatterji, D., and Ojha, A. K. (2001). Revisiting the stringent response, ppGpp and starvation signaling. Curr. Opin. Microbiol. 4, 160-165. doi: 10.1016/ s1369-5274(00)00182-x

Cohen, S. S., and Barner, H. D. (1956). Studies on the induction of thymine deficiency and on the effects of thymine and thymidine analogues in Escherichia coli. J. Bacteriol. 71, 588-597. doi: 10.1128/jb.71.5.588597.1956

Corrigan, R. M., Bellows, L. E., Wood, A., and Gruendling, A. (2016). ppGpp negatively impacts ribosome assembly affecting growth and antimicrobial tolerance in Gram-positive bacteria. Proc. Natl. Acad. Sci. U. S. A. 113, E1710-E1719. doi: 10.1073/pnas.1522179113

Cossins, E. (2000). The fascinating world of folate and one-carbon metabolism. Can. J. Bot. 78, 691-708. doi: 10.1139/cjb-78-6-691

Cox, M. M. (2000). "Recombinational DNA repair in bacteria and the RecA protein" in Progress in Nucleic Acid Research and Molecular Biology. ed. K. Moldave, Vol. 63, (SAN DIEGO, CA: Academic press), 311-366.

Datsenko, K. A., and Wanner, B. L. (2000). One-step inactivation of chromosomal genes in Escherichia coli K-12 using PCR products. Proc. Natl. Acad. Sci. U. S. A. 97, 6640-6645. doi: 10.1073/pnas.120163297

Datta, K., Purkayastha, S., Neumann, R. D., Pastwa, E., and Winters, T. A. (2011). Base damage immediately upstream from double-strand break ends is a more severe impediment to nonhomologous end joining than blocked 3'-termini. Radiat. Res. 175, 97-112. doi: 10.1667/Rr2332.1

Dizdaroglu, M., Jaruga, P., Birincioglu, M., and Rodriguez, H. (2002). Free radical-induced damage to DNA: mechanisms and measurement. Free Radic. Biol. Med. 32, 1102-1115. doi: 10.1016/S0891-5849(02)00826-2

Dutta, N. K., Klinkenberg, L. G., Vazquez, M. J., Segura-Carro, D., Colmenarejo, G., Ramon, F., et al. (2019). Inhibiting the stringent response blocks mycobacterium tuberculosis entry into quiescence and reduces persistence. Sci. Adv. 5:eaav2104. doi: 10.1126/sciadv.aav2104

Dwyer, D. J., Belenky, P. A., Yang, J. H., MacDonald, I. C., Martell, J. D., Takahashi, N., et al. (2014). Antibiotics induce redox-related physiological alterations as part of their lethality. Proc. Natl. Acad. Sci. U. S. A. 111, E2100-E2109. doi: 10.1073/pnas.1401876111

Dwyer, D. J., Kohanski, M. A., and Collins, J. J. (2009). Role of reactive oxygen species in antibiotic action and resistance. Curr. Opin. Microbiol. 12, 482-489. doi: $10.1016 /$ j.mib.2009.06.018

Flint, D. H., Tuminello, J., and Emptage, M. (1993). The inactivation of Fe-S cluster containing hydrolyases by superoxide. J. Biol. Chem. 268, 22369-22376. doi: 10.1016/S0021-9258(18)41538-4

Foti, J. J., Devadoss, B., Winkler, J. A., Collins, J. J., and Walker, G. C. (2012). Oxidation of the guanine nucleotide pool underlies cell death by bactericidal antibiotics. Science 336, 315-319. doi: 10.1126/science.1219192

Gaudilliere, J. P. (2009). The first miracle drugs: how the sulfa drugs transformed medicine. Bull. Hist. Med. 83, 218-220. doi: 10.1353/bhm.0.0197 
Giroux, X., Su, W. L., Bredeche, M. F., and Matic, I. (2017). Maladaptive DNA repair is the ultimate contributor to the death of trimethoprim-treated cells under aerobic and anaerobic conditions. Proc. Natl. Acad. Sci. U. S. A. 114, 11512-11517. doi: 10.1073/pnas.1706236114

Grunberg, E., and DeLorenzo, W. F. (1966). Potentiation of sulfonamides and antibiotics by trimethoprim [2,4-diamino-5-(3,4,5-trimethoxybenzyl) pyrimidine]. Antimicrob. Agents Chemother. 6, 430-433.

Gutteridge, J. M. (1990). Superoxide-dependent formation of hydroxyl radicals from ferric-complexes and hydrogen peroxide: an evaluation of fourteen iron chelators. Free Radic. Res. Commun. 9, 119-125. doi: 10.3109/ 10715769009148579

Henderson, G. B., and Huennekens, F. M. (1986). "Membrane-associated folate transport proteins," in Methods in Enzymology, eds. F. Chytil and D. B. McCormick, (London, England: Academic Press Ltd- Elsevier Science), 260-269.

Hieke, A. S. C., and Pillai, S. D. (2018). Escherichia coli cells exposed to lethal doses of electron beam irradiation retain their ability to propagate bacteriophages and are metabolically active. Front. Microbiol. 9:11. doi: 10.3389/fmicb.2018.02138

Honsa, E. S., Cooper, V. S., Mhaissen, M. N., Frank, M., Shaker, J., Iverson, A., et al. (2017). RelA mutant enterococcus faecium with multiantibiotic tolerance arising in an immunocompromised host. MBio 8, e02124-e02116. doi: 10.1128/mBio.02124-16

Imlay, J. A. (2003). Pathways of oxidative damage. Annu. Rev. Microbiol. 57, 395-418. doi: 10.1146/annurev.micro.57.030502.090938

Imlay, J. A., Chin, S. M., and Linn, S. (1988). Toxic DNA damage by hydrogen peroxide through the fenton reaction in vivo and in vitro. Science 240, 640-642. doi: 10.1126/science.2834821

Imlay, J. A., and Fridovich, I. (1991). Assay of metabolic superoxide production in Escherichia coli. J. Biol. Chem. 266, 6957-6965. doi: 10.1016/ S0021-9258(20)89596-9

Jena, N. R. (2012). DNA damage by reactive species: mechanisms, mutation and repair. J. Biosci. 37, 503-517. doi: 10.1007/s12038-012-9218-2

Khodursky, A., Guzman, E. C., and Hanawalt, P. C. (2015). "Thymineless death lives on: new insights into a classic phenomenon," in Annual Review of Microbiology. ed. S. Gottesman, vol. 69, (PALO ALTO, CA: Annual Reviews), 247-263.

Kim, H. Y., Go, J., Lee, K.-M., Oh, Y. T., and Yoon, S. S. (2018). Guanosine tetra- and pentaphosphate increase antibiotic tolerance by reducing reactive oxygen species production in Vibrio cholerae. J. Biol. Chem. 293, 5679-5694. doi: 10.1074/jbc.RA117.000383

Kogoma, T., Hong, X., Cadwell, G. W., Barnard, K. G., and Asai, T. (1993). Requirement of homologous recombination functions for viability of the Escherichia-coli cell that lacks rnase-Hi and exonuclease- $\mathrm{V}$ activities. Biochimie 75, 89-99. doi: 10.1016/0300-9084(93)90029-R

Kohanski, M. A., Dwyer, D. J., Hayete, B., Lawrence, C. A., and Collins, J. J. (2007). A common mechanism of cellular death induced by bactericidal antibiotics. Cell 130, 797-810. doi: 10.1016/j.cell.2007.06.049

Kohanski, M. A., Dwyer, D. J., Wierzbowski, J., Cottarel, G., and Collins, J. J. (2008). Mistranslation of membrane proteins and two-component system activation trigger antibiotic-mediated cell death. Cell 135, 679-690. doi: 10.1016/j.cell.2008.09.038

Kompis, I. M., Islam, K., and Then, R. L. (2005). DNA and RNA synthesis: antifolates. Chem. Rev. 105, 593-620. doi: 10.1021/cr0301144

Kuong, K. J., and Kuzminov, A. (2010). Stalled replication fork repair and misrepair during thymineless death in Escherichia coli. Genes Cells 15, 619-634. doi: 10.1111/j.1365-2443.2010.01405.x

Lobritz, M. A., Belenky, P., Porter, C. B. M., Gutierrez, A., Yang, J. H., Schwarz, E. G., et al. (2015). Antibiotic efficacy is linked to bacterial cellular respiration. Proc. Natl. Acad. Sci. U. S. A. 112, 8173-8180. doi: 10.1073/pnas.1509743112

Lu, A. L., Li, X. H., Gu, Y. S., Wright, P. M., and Chang, D. Y. (2001). Repair of oxidative DNA damage - mechanisms and functions. Cell Biochem. Biophys. 35, 141-170. doi: 10.1385/Cbb:35:2:141

Mahaseth, T., and Kuzminov, A. (2016). Prompt repair of hydrogen peroxideinduced DNA lesions prevents catastrophic chromosomal fragmentation. DNA Repair 41, 42-53. doi: 10.1016/j.dnarep.2016.03.012

Manna, M. S., Tamer, Y. T., Gaszek, I., Poulides, N., Ahmed, A., Wang, X., et al. (2021). A trimethoprim derivative impedes antibiotic resistance evolution. Nat. Commun. 12, 2949. doi: 10.1038/s41467-021-23191-z

Murray, B. E., Rensimer, E. R., and Dupont, H. L. (1982). Emergence of highlevel trimethoprim resistance in fecal Escherichia coli during oral administration of trimethoprim or trimethoprim-sulfamethoxazole. N. Engl. J. Med. 306, 130-135. doi: 10.1056/NEJM198201213060302

Nakanishi-Matsui, M., Sekiya, M., and Futai, M. (2016). ATP synthase from Escherichia coli: mechanism of rotational catalysis, and inhibition with the $\varepsilon$ subunit and phytopolyphenols. Biochim. Biophys. Acta 1857, 129-140. doi: 10.1016/j.bbabio.2015.11.005

Neeley, W. L., and Essigmann, J. M. (2006). Mechanisms of formation, genotoxicity, and mutation of guanine oxidation products. Chem. Res. Toxicol. 19, 491-505. doi: 10.1021/tx0600043

Nguyen, D., Joshi-Datar, A., Lepine, F., Bauerle, E., Olakanmi, O., Beer, K., et al. (2011). Active starvation pesponses mediate antibiotic tolerance in biofilms and nutrient-limited bacteria. Science 334, 982-986. doi: 10.1126/ science. 1211037

Noster, J., Persicke, M., Chao, T.-C., Krone, L., Hensel, M., and Hansmeier, N. (2019). Impact of ROS-induced damage of TCA cycle enzymes on metabolism and virulence of Salmonella enterica serovar Typhimurium. Front. Microbiol. 10:762. doi: 10.3389/fmicb.2019.00762

Pankey, G. A., and Sabath, L. D. (2004). Clinical relevance of bacteriostatic versus bactericidal mechanisms of action in the treatment of gram-positive bacterial infections. Clin. Infect. Dis. 38, 864-870. doi: $10.1086 / 381972$

Potrykus, K., Murphy, H., Philippe, N., and Cashel, M. (2011). ppGpp is the major source of growth rate control in E. coli. Environ. Microbiol. 13, 563-575. doi: $10.1111 / \mathrm{j} .1462-2920.2010 .02357 . \mathrm{x}$

Repine, J., Fox, R. B., and Berger, E. (1981). Hydrogen peroxide kills Staphylococcus aureus by reacting with staphylococcal iron to form hydroxyl radical. J. Biol. Chem. 256, 7094-7096. doi: 10.1016/S0021-9258(19)68927-1

Rocha, E. P. C., Cornet, E., and Michel, B. (2005). Comparative and evolutionary analysis of the bacterial homologous recombination systems. PLoS Genet. 1:e15. doi: 10.1371/journal.pgen.0010015

Schnetterle, M., Gorge, O., Nolent, F., Boughammoura, A., Sarilar, V., Vigier, C., et al. (2021). Genomic and RT-qPCR analysis of trimethoprim-sulfamethoxazole and meropenem resistance in Burkholderia pseudomallei clinical isolates. PLoS Negl. Trop. Dis. 15:e0008913. doi: 10.1371/journal.pntd.0008913

Seydel, J. K. (1968). Sulfonamides, structure-activity relationship, and mode of action: structural problems of the antibacterial action of 4-aminobenzoic acid (PABA) antagonists. J. Pharm. Sci. 57, 1455-1478. doi: 10.1002/ jps.2600570902

Singh, N. P., Stephens, R. E., Singh, H., and Lai, H. (1999). Visual quantification of DNA double-strand breaks in bacteria. Mutat. Res. 429, 159-168. doi: 10.1016/S0027-5107(99)00124-4

Solanky, D., and Haydel, S. E. (2012). Adaptation of the neutral bacterial comet assay to assess antimicrobial-mediated DNA double-strand breaks in Escherichia coli. J. Microbiol. Methods 91, 257-261. doi: 10.1016/j.mimet.2012.08.009

Srivatsan, A., and Wang, J. D. (2008). Control of bacterial transcription, translation and replication by (p)ppGpp. Curr. Opin. Microbiol. 11, 100-105. doi: 10.1016/j.mib.2008.02.001

Takahashi, H., Nishina, A., Fukumoto, R.-H., Kimura, H., Koketsu, M., and Ishihara, H. (2005). Selenoureas and thioureas are effective superoxide radical scavengers in vitro. Life Sci. 76, 2185-2192. doi: 10.1016/j.lfs. 2004.08.037

ter Kuile, B. H., and Hoeksema, M. (2018). Antibiotic killing through incomplete DNA repair. Trends Microbiol. 26, 2-4. doi: 10.1016/j.tim.2017.11.006

Then, R. L. (1980). Role of thymidine for the activity of trimethoprim, sulfonamides and their combinations. Zentralbl. Bakteriol. A 247, 483-494.

Then, R., and Angehrn, P. (1973). Sulfonamide-induced thymineless death in Escherichia coli. J. Gen. Microbiol. 76, 255-263. doi: 10.1099/00221287-76-2-255

Toulouse, J. L., Shi, G., Lemay-St-Denis, C., Ebert, M., Deon, D., Gagnon, M., et al. (2020). Dual-target inhibitors of the Folate pathway inhibit intrinsically trimethoprim-resistant DfrB dihydrofolate reductases. ACS Med. Chem. Lett. 11, 2261-2267. doi: 10.1021/acsmedchemlett.0c00393

Tseng, C.-P., Yu, C.-C., Lin, H.-H., Chang, C.-Y., and Kuo, J.-T. (2001). Oxygenand growth rate-dependent regulation of Escherichia coli fumarase (FumA, FumB, and FumC) activity. J. Bacteriol. 183, 461-467. doi: 10.1128/ JB.183.2.461-467.2001

van de Wier, B., Balk, J. M., Haenen, G. R., Giamouridis, D., Bakker, J. A., Bast, B. C., et al. (2013). Elevated citrate levels in non-alcoholic fatty liver disease: the potential of citrate to promote radical production. FEBS Lett. 587, 2461-2466. doi: 10.1016/j.febslet.2013.06.019 
Vogel, H. J., and Bonner, D. M. (1956). Acetylornithinase of Escherichia coli partial purification and some properties. J. Biol. Chem. 218, 97-106. doi: 10.1016/S0021-9258(18)65874-0

Wang, L., Ouyang, B. J., Li, Y. F., Feng, Y. G., Jacquot, J. P., Rouhier, N., et al. (2012). Glutathione regulates the transfer of iron-sulfur cluster from monothiol and dithiol glutaredoxins to apo ferredoxin. Protein Cell 3(9), 714-721. doi: 10.1007/s13238-012-2051-4

Yi, H., and Kim, H. S. (2018). Antibiotic scars left on the gut microbiota from the stringent response. Trends Microbiol. 26, 735-737. doi: 10.1016/j.tim.2018.06.003

Conflict of Interest: The authors declare that the research was conducted in the absence of any commercial or financial relationships that could be construed as a potential conflict of interest.
Publisher's Note: All claims expressed in this article are solely those of the authors and do not necessarily represent those of their affiliated organizations, or those of the publisher, the editors and the reviewers. Any product that may be evaluated in this article, or claim that may be made by its manufacturer, is not guaranteed or endorsed by the publisher.

Copyright (c) 2021 Si, Gu, Wen, Wang, Fleming, Li, Xu, Bi and Deng. This is an open-access article distributed under the terms of the Creative Commons Attribution License (CC BY). The use, distribution or reproduction in other forums is permitted, provided the original author(s) and the copyright owner(s) are credited and that the original publication in this journal is cited, in accordance with accepted academic practice. No use, distribution or reproduction is permitted which does not comply with these terms. 